\title{
A Importância do Setor Externo para a Inflação Brasileira: \\ uma estimação para o período 2001-2013.
}

\author{
Karla Vanessa B. S. Leite* \\ Jennifer Hermann ${ }^{\dagger}$ \\ Débora Pimentel ${ }^{\ddagger}$
}

\begin{abstract}
Resumo
Partindo da hipótese de que, a partir das políticas de liberalização dos anos 1980-90, os fatores externos ampliaram sua importância na dinâmica inflacionária doméstica, o presente artigo estima uma equação de inflação para a economia brasileira, no período compreendido entre 2001 e 2013, com foco nas variáveis do setor externo. A estimação tem por base analítica o modelo de inflação de Smonsen (1970) e foi feita através dos modelos de Vetores Auto Regressivos Estruturais (SVAR) e de Defasagem Distribuída (ARDL). Os resultados da análise econométrica, nos dois modelos estimados, apontaram para a importância da taxa de câmbio, dos preços externos e da volatilidade cambial na explicação da evolução da inflação brasileira, entre 2001 e 2013.
\end{abstract}

Palavraschave: Inflação, Setor Externo, Economia Brasileira.

\begin{abstract}
Assuming that from the financial liberalization policy of the 1980-90s, external factors have increased their importance in explaining domestic inflation dynamics, the paper estimates an inflation equation for the Brazilian economy in the period between 2001 and 2013, focusing on the variables of the external sector. The estimation was based on the Smonsen (1970)'s inflation model and on two econometric models: the Stuctural and the Distributed-Lag Auto Regressive Vectors models (SVAR and ARDL). The results of the econometric analysis, in the two models estimated, pointed to the importance of the exchange rate, external price and exchange rate volatility in explaining the evolution of Brazilian inflation between 2001 and 2013.
\end{abstract}

Keywords: Inflation, External Sector, Brazilian Economy.

HQ⿱日一)assification: E31, E44, F62

\footnotetext{
*Professora Adjunta da UFOG. kvanessaleite@gmail.com

${ }^{\dagger}$ Professora Associada da URR jenniferbr1508@gmail.øm

${ }^{\ddagger}$ Doutoranda do IEI URR deboramp@globo.com
} 


\section{Introdução}

Os anos 1980-90 foram um marco para as economias capitalistas, no que tange a seu modo de inserção externa. As políticas de liberalização implementadas nesse período, em escala mundial, ampliaram acentuadamente seu grau de abertura comercial e financeira, tornandoas mais sensíveis ao cenário externo. A liberalização, que, expressamente, visava ampliar a capacidade de crescimento econômico dos países envolvidos - objetivo nem sempre alcançado - afetou também variáveis macroeconômicas importantes neste processo, como as taxas de juros, de câmbio e de inflação. Nesse debate, o presente artigo analisa os efeitos dessa nova institucionalidade sobre o comportamento da inflação, com foco no caso brasileiro.

O setor externo impacta os preços domésticos, essencialmente, por meio de dois canais de influência sobre os custos de produção: a taxa de câmbio e os preços internacionais. A maior abertura comercial reforça os vínculos entre a inflação de cada país e os preços internacionais. A abertura financeira, por sua vez, torna as taxas de câmbio mais sensíveis aos fluxos internacionais de capital. Além disso, o que se verifica a partir dosanos 2000 , na maioria dos países, é a coexistência de ampla abertura comercial e financeira œom regimes de câmbio flutuante. Os efeitos dessa nova institucionalidade são, assim, potencializados, na medida em que: i) a maior abertura comercial torna os preços domésticos mais sensíveis aos preços internacionais; ii) a flexibilidade cambial torna a taxa de câmbio uma influência frequente sobre os preços domésticos; iii) a abertura financeira, combinada ao regime de câmbio flutuante, torna a taxa de câmbio mais sujeita a oscilações. En conjunto, essas condições tornam as economias abertas mais propensas à inflação (ou deflação) de custos, pela via do setor externo.

O Brasil, como se sabe, não foi uma exceção, tendo passado também por amplo processo de liberalização comercial e financeira a partir de fins dos anos $1980 .{ }^{1}$ Esse novo contexto, provavelmente, afetou o país nos moldes antes descritos, tornando a inflação brasileira mais permeável aos movimentos da taxa de câmbio e dos preços internacionais. Partindo dessa hipótese, o presente artigo estima uma equação de inflação para o Brasil, visando avaliar a contribuição do setor externo para a inflação brasileira no período pósliberal ização. Em razão da disponibilidade de dados, esse período é aqui representado pelos anos 2001-2013.

No plano teórico-analítico, toma-se por base para essa estimação o modelo proposto por Smonsen (1970), que desagrega a inflação em três grandes componentes: a) de demanda, que reflete as pressões do crescimento econômico; b) autônomo, que reflete as pressões de custos; c) de realimentação inflacionária, via inércia e expectativas de inflação. Além de sua abrangência na captação de possiveis pressões inflacionárias, esse enfoque se mostra particularmente adequado à análise aqui proposta, por explicitar um componente de custos, que (entre outras) capta a influência das variáveis foco desse estudo: a taxa de câmbio e os preços internacionais.

No plano econométrico, a estimação é feita através do modelo de Vetores Auto Regressivos Estruturais (SVAR) e do modelo Auto Regressivo de Defasagem Distribuída (ARDL). OVARe ARDL são, ambos, modelos autorregressivos. A principal diferença ente eles reside no fato de que o VARé um vetor de variáveis, um sistema de equações, ao invés de uma única equação, œmo no caso do ARDL A opção por utilizar os dois modelos visa conferir maior

\footnotetext{
${ }^{1}$ Sobre o processo de liberalização financeira no Brasil ver, entre outros, Freitas(1999), Hermann (2005) e De Paula (2011). Sobre o processo de abertura comercial, consultar, entre outros, Azevedo e Portugal (1998), Kume e Patrício (1987), Fritsch e Franco (1991) e Kume, Piane e Souza (2003).
} 
robustez ao estudo: se os resultados encontrados forem, semelhantes, pode-se inferir que os mesmos são robustos ao método de estimação.

Oartigo é desenvolvido em mais 4 seçães, além dessa Introdução. A seção 2 descreve brevemente o modelo de inflação de Smonsen (1970). A seção 3 apresenta a equação de inflação, adaptada do modelo de Smonsen (1970), descreve a base de dados e discute, brevemente, o método utilizado para estimar a equação. Na seção 4, são apresentados e discutidos os resultados da estimação. A seção 5 sumaria e conclui o artigo.

\section{O modelo de Inflação de Smonsen (1970)}

Smonsen (1970) desenvolve um modelo analítico para explicar processos de inflação crônica em geral resistentes a políticas de restrição de demanda, que se tornaram comuns nos países em desenvolvimento a partir dos anos 1960. Como o próprio autor esclarece, não se trata exatamente de uma nova teoria de inflação, mas sim do que chamou de "uma moldura teórica um pouco mais sofisticada" (Smonsen, 1970, p. 127), que

"[...] vale mais como uma descrição didática do que como uma expressão precisa da formação da taxa inflacionária [e] constituiu uma simplificação conveniente para os testes econométricos e para as descrições exemplificativas [...]"(idem, p. 129).

Smonsen (1970) distinguiu três componentes do processo inflacionário, quais sejam: i) uma componente autônoma em relação à demanda agregada, que representa a influência dos custos; ii) uma componente de realimentação, que pode surgir em uma economia já inflacionária, que desenvolveu comportamentos defensivos em relação à perda de renda real $\mathrm{e}$ iii) uma componente de demanda agregada, relacionada ao excesso de demanda sobre a oferta agregada.

A componente autônoma expressa o peso dos custos na variação dos preços dos bens finais. Integram este item, basicamente, os custos relativos a salários, matérias primas e insumos industriais de origem doméstica e externa, impostos indiretos, juros, taxa de câmbio, entre outros. Embora possam refletir, em parte, pressões de demanda - captadas, no modelo, pela componente específica - esses custos são tratados como pressões autônomas sobre os preços porque sofrem grande influência de fatores estruturais (escassez de capacidade produtiva em setores específicos, por exemplo), institucionais (caso dosimpostos, saláriose da taxa de câmbio, ou de eventos totalmente exógenos (como choques de oferta decorrentes de quebras de safra agrícola ou mudanças nos preços internacionais ou nos fluxos de capital). ${ }^{2}$

A componente de realimentação, como o termo indica, reflete a influência da própria inflação (recente) sobre os preços. Essa influência se materializa em mais inflação diante da combinação de duas condições: a) dos ef eitos distributivos da inflação, que impõem perdas de renda real para alguns agentes e ganhos para outros; b) da tentativa de recomposição de renda real por parte dos "perdedores". Assim, a componente de realimentação inflacionária torna-se quantitativamente mais relevante em economias submetidas a taxas de inflação mais altas (que elevam as perdas reais) e que disponham de condições facilitadoras da

\footnotetext{
${ }^{2}$ Nos regimes de câmbio administrado a taxa de câmbio é obviamente uma variável institucional e autônoma, cuja meta é definida pelo governo. Nos regimes de câmbio flutuante a própria escolha deste modelo de regime cambial é, em si, uma condição institucional e os movimentos da taxa de câmbio refletem, essencialmente, a influência de variáveis externas (e exógenas), associadas ao comércio e ao fluxo de capital internacionais.
} 
recomposição de salários e lucros (como mecanismos formais ou informais de indexação de preços e contratos, mercados oligopolizados, entre outros).

A componente de demanda atua como um elemento regulador das pressões de custos e de realimentação sobre a inflação. Quando a demanda cresce a um ritmo inferior ao do produto potencial - isto é, se o hiato do produto é positivo - a inflação é predominantemente explicada pelos componentes de custo e (se houver) de realimentação. Neste caso, a contribuição da demanda para a inflação é menor e se dá apenas de forma setorial, através dos setores que mais precocemente atingem o nível de pleno emprego. No entanto, se a demanda crescer em ritmo superior ao da capacidade produtiva da economia - ou seja, em caso de excesso de demanda agregada - a inflação será maior do que aquela que resultaria das componentes autônomas e de realimentação.

Formalmente, numa versão linear proposta pelo próprio autor (Smonsen, 1970, p. 128), a taxa de inflação $\left(\mathbf{r}_{\mathbf{t}}\right)$ pode ser expressa da seguinte forma:

$r_{\mathrm{t}}=\mathrm{a}_{\mathrm{t}}+\mathrm{br}_{\mathrm{t}-1}+\mathrm{c}\left[\frac{\mathrm{d}_{\mathrm{t}}}{\mathrm{d}_{\mathrm{t}-1}^{*}}-1-\mathrm{n}\right]$

Onde: $\mathbf{a}_{\mathbf{t}}=$ inflação autônoma no período t;

$\mathbf{b r}_{\mathrm{t}-\mathbf{1}}=$ componente de realimentação;

c $\left[\frac{\mathrm{d}_{\mathrm{t}}}{\mathbf{d}_{\mathrm{l}-1}^{*}}-\mathbf{1}-\mathbf{n}\right]_{=\text {componente de demanda; }}$

$\mathbf{d}_{\mathbf{t}}=$ demanda agregada no período $\mathrm{t}$;

$\mathrm{d}_{\mathrm{t}-1}^{*}=$ demanda agregada (igual à oferta agregada) em $\mathrm{t}-1$;

b, ce $\mathbf{n}$ são parâmetros.

O parâmetro b "indica o grau de automatismo da inflação crônica", ou seja, "em que fração a inflação de um período se transmite ao período seguinte" (Smonsen, 1970, p. 129). Embora admita a hipótese de $b>1$ nos casos de processos explosivos de hiperinflação, Smonsen supõe que, no caso geral, $0<b<1$, indicando que a parcela transmitida se mantém inferior à taxa de inflação do período anterior. O mesmo pode-se supor para o parâmetro c $(0$ $<c<1$ ), sendo este influenciado, essencialmente, pelo grau de concorrência dos mercados (quanto maior a concorrência, menor tende a ser $\mathrm{c}$ ). $\mathrm{O}$ parâmetro $\mathbf{n}$ corresponde à "taxa normal de crescimento da procura" (Smonsen, 1970, p. 129) e indica a taxa de crescimento da demanda que estabiliza os preços, na ausência de inflação prévia e autônoma - ou seja, a taxa que "cabe" nos limites do produto potencial, correspondente à ausência de excesso de demanda.

A utilização do modelo Smonsen (1970) como base para a estimação a que se propõe este artigo requer algumas adaptações. Mais especificamente, é necessário explicitar, em cada componente, as variáveis do setor externo que, em tese, cumpram duas condições simultaneamente: a) sejam afetadas pela ampliação do grau de abertura econômica (englobando a comercial e a financeira); b) sejam relevantes na formação dos preços e, consequentemente, de processos inflacionários. Essa análise é desenvolvida na seção seguinte. 


\section{Estimação da Equação de Inflação}

\subsection{Variáveis do Modelo}

No componente de demanda do modelo de Smonsen (1970), a influência do setor externo sobre os preços domésticos será analisada através do comportamento do saldo da

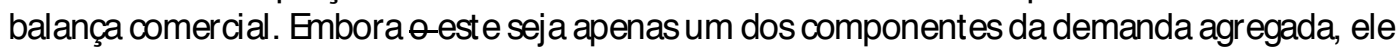
é um importante canal pelo qual a abertura comercial e financeira pode afetar a demanda agregada e, através dela, a inflação. No entanto, œmo as exportaçães tem baixo peso relativo na demanda agregada no Brasil (Freitas e Dweck, 2013), espera-se que o impacto do saldo da balança comercial sobre a inflação seja pequeno.

No componente autônomo, serão explicitados a taxa de câmbio e os preços internacionais, já que estes são os principais canais através dos quais o setor externo influencia a dinâmica dos preços domésticos pela via dos custos.

No componente de realimentação, serão explicitadas as expectativas e a inércia inflacionárias. Embora estas não sejam produto direto da abertura econômica, elas são canais importantes de influência das variáveis externas. O processo de globalização tende a tornar mais voláteis a taxa de câmbio e os preços internacionais. Essa volatilidade produz incerteza que, por sua vez, tende a se materializar nas expectativas inflacionárias. Assume-se, portanto, a hipótese de que as expectativas inflacionárias são, em parte, uma função da volatilidade da taxa de câmbio. A inércia inflacionária, desde a década de 1970, é amplamente reconhecida como um fator relevante para o comportamento dos preços no Brasil, na medida em que propaga as pressões de custo. Neste caso, assumindo que a parcela da inflação explicada por sua própria variância pode ser "interpretada como uma medida de inércia inflacionária" (Modenesi e Araújo, 2010b, p. 12), a análise foi feita a partir da decomposição da variância do IPCA. $^{3}$

Por fim, reconhecendo que a inflação não é afetada apenas pelas variáveis aqui priorizadas, em todos os componentes será inserida uma variável representativa dos demais fatores que af etam a inflação e que não estão, pelo menos diretamente, relacionados aos fatores externos.

De acordo com essas especificações, a inflação pode ser formalmente representada pela equação:

$\pi=\left(a \cdot B C+b \cdot \theta_{D}\right)+\left(c \cdot P I N+d \cdot T C+e \cdot \theta_{A}\right)+\left(f \cdot E X\left(V O L+g \cdot \theta_{E}\right)+h \cdot I N E+i \cdot \theta_{R}\right)$

Onde:

\section{a, $\boldsymbol{b}, \boldsymbol{c}, \boldsymbol{d}, \boldsymbol{e}, \boldsymbol{f}, \boldsymbol{g}$, hei são constantes;}

BC. Saldo da balança comercial;

PIN: Preços internacionais;

TC. Variação da taxa de câmbio;

EX: Expectativas inflacionárias;

VOL: Volatilidade da taxa de câmbio;

INE: Inércia inflacionária;

\footnotetext{
${ }^{3}$ Fuhrer (2009) examina o conceito de persistência inflacionária na teoria macroeconômica, indicando algumas medidas empíricas para mensurar a inércia.
} 
$\theta_{D}$ : Outras variáveis de demanda (taxa de crescimento do PIB ou da renda agregada, hiato do produto, expansão do consumo, déficit público nominal, entre outras);

$\theta_{A}$ : Outras variáveis autônomas (comportamento dos salários nominais, produtividade, choques de oferta, entre outras);

$\theta_{E}$ : Outrasvariáveis que afetam as expectativas de inflação (resultado fiscal da economia, comportamento da taxa de juros, entre outros);

$\theta_{R}$ : Outras variáveis de realimentação (componente inercial).

Com base na equação (2), estima-se uma equação de inflação para os anos 2001-13 no Brasil, por meio da modelagem de Vetores Auto Regressivos (VAR) e do modelo Auto Regressivo de Defasagem Distribuída (ARDL).

\subsection{Base de Dados}

As séries utilizadas nas estimações são de periodicidade mensal e compreendem o período entre janeiro de 2001 e dezembro de 2013, totalizando 156 observações. Trata-se, portanto, de uma amostra suficiente para conferir confiabilidade aos resultados (Greene, 2003, Cap. 9). O quadro 1 descreve a base de dados da estimação ${ }^{4}$.

Quadro 1 - Descrição dos dados utilizados no modelo

\begin{tabular}{|c|c|c|}
\hline Variável & Descrição & Fonte \\
\hline Inflação (INFL) & $\begin{array}{l}\text { Índice de Preços ao Consumidor Amplo } \\
\text { - variação percentual mensal }\end{array}$ & $\begin{array}{l}\text { Instituto } \text { Brasileiro de } \\
\text { Geografia e } \text { Estatística } \\
\text { (IBGE) }\end{array}$ \\
\hline $\begin{array}{l}\text { Balança Comercial } \\
\text { (BO) }\end{array}$ & $\begin{array}{l}\text { Saldo mensal da balança comercial em } \\
\text { US\$ }\end{array}$ & $\begin{array}{l}\text { Banco Central do Brasil } \\
\text { (BCB) }\end{array}$ \\
\hline Expectativas (EXPEC) & $\begin{array}{l}\text { Expectativas no mês para a inflação } \\
\text { mensal - média dos relatórios semanais } \\
\text { Focus }\end{array}$ & $\begin{array}{l}\text { Relatório Focus - Banco } \\
\text { Central do Brasil (BCB) }\end{array}$ \\
\hline $\begin{array}{l}\text { Preços externos } \\
\text { (PEXT) }\end{array}$ & Índice de commodities em US\$ & $\begin{array}{l}\text { Fundo Monetário } \\
\text { Internacional (FMI) }\end{array}$ \\
\hline $\begin{array}{l}\text { Taxa de Câmbio } \\
\text { (CAMBIO) }\end{array}$ & Média mensal da taxa PTAX-R\$/US\$ & $\begin{array}{l}\text { Banco Central do Brasil } \\
\text { (BCB) }\end{array}$ \\
\hline $\begin{array}{l}\text { Volatilidade da Taxa } \\
\text { de Câmbio (VOL) }\end{array}$ & $\begin{array}{l}\text { Variância mensal da taxa de câmbio } \\
\text { PTAX }\end{array}$ & 日aboração Própria \\
\hline Inércia (INE) & $\begin{array}{l}\text { A inércia foi analisada a partir da } \\
\text { decomposição da variância da série do } \\
\text { IPCA. }\end{array}$ & 日aboração Própria \\
\hline
\end{tabular}

Fonte: Eaboração Própria (out/2014).

\footnotetext{
${ }^{4}$ Para fornecer ao leitor uma visão geral das variáveis do modelo, no período analisado, a tabela 6 do anexo traz um resumo da estatística descritiva.
} 
As séries de inflação e expectativas de inflação apresentaram elevado grau de correlação. Os testes de causalidade de Granger $^{5}$ indicaram que expectativas de inflação e volatilidade cambial apresentam relações causais entre si, corroborando a hipótese, antes mencionada, de que as expectativas são, em parte, função da volatilidade da taxa de câmbio.

\subsection{Metodologia}

Como já observado, a principal diferença entre os modelos VARe ARDL aqui utilizados reside no fato de que o modelo VARé um vetor de variáveis, um sistema de equações, ao invés de uma única equação, como no caso do AR Os modelos uniequacionais autorregressivos de defasagens distribuídas têm a vantagem de permitir maior flexibilidade na modelagem da dinâmica de defasagens, permitindo a imposição de números diferentes de defasagens para cada uma das variáveis explicativas. Isto confere maior flexibilidade para o tratamento de possíveis quebras estruturais verificadas ao longo de uma ou mais das séries temporais envolvidas, ou até mesmo na relação entre as séries.

Os modelos uniequacionais têm a desvantagem de requerer que se defina previamente a variável endógena ao modelo, tratando as demais como exógenas. Essa restrição pode ser contornada através da estimação de modelos de vetores autorregressivos (VAR), que, em vez de uma única equação, é formado por um sistema de equações, onde todas as variáveis são endógenas. Uma limitação desse modelo, porém, é o elevado número de parâmetros decorrentes, o que pode se refletir no tamanho da amostra necessária para que se tenha uma estimação confiável.

Como fica claro, embora semelhantes, cada modelo tem vantagens e desvantagens distintas. Assim, a estimação com base nos dois modelos torna mais robustos os resultados. Vale destacar que a questão das quebras estruturais é bastante relevante, no caso das séries temporais brasileiras, seja pela própria dinâmica da economia ou pela ocorrência de mudanças metodológicas na apuração dos dados pelos órgãos oficiais. A partir de 2004, foram implementadas mudanças nos setores de energia elétrica, telefonia e combustíveis que reduziram a indexação dos contratos ao IGP e podem ter diminuído, por essa via, o peso do setor externo para explicar o IPCA. Sendo assim, optou-se por estimar os modelos em dois períodos, supondo uma quebra estrutural na relação entre as séries em dezembro de 2004. Logo, as estimações foram feitas para o período completo (jan/2001 a dez/2013) e para dois subperíodos, quais sejam: jan/2001 a dez/2004 e jan/2005 a dez/2013. ${ }^{6}$ Os resultados da estimação para o período 2001-2013 encontram-se expostos nas próximas seções. Já os resultados para os dois subperíodos estão disponíveis no anexo.

As equações dos modelos estimados foram as seguintes ${ }^{7}$ :

a) Modelo ARDL-jan/2001 a dez/2013:

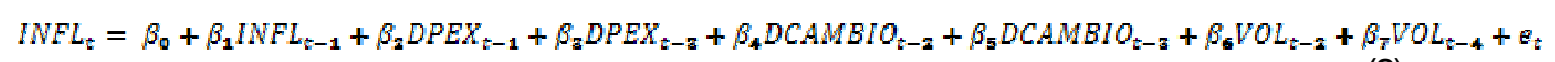

\footnotetext{
${ }^{5}$ Resultados no anexo.

${ }^{6}$ Foi realizado o teste de quebra estrutural de Chow no modelo ARDL, a hipótese nula de ausência de quebra estrutural em dezembro de 2014 foi rejeitada. O resultado do test e se encontra na Tabela 8 do anexo.

${ }^{7}$ Para fazer as est imações for am utilizados os seguintes softwares. R, Eviews 7 e OxMetrics 6. Os testes de raiz unitária e cointegração foram feitos no $\mathrm{R}$ o modelo SVAR foi estimado no Eviews 7 e o modelo ARDLfoi estimado no OxMetrics6.
} 
b) Modelo ARDL-Período 1: jan/2001 a dez/2004:

$$
\begin{gathered}
I N F L_{t}=\beta_{0}\left|\beta_{2} I N F L_{t-1}\right| \beta_{1} D C A M E I O_{t-2}\left|\beta_{2} V O L_{t-2}\right| \beta_{3} V O L_{t-4} \mid e_{t} \\
\text { c) Modelo ARDL-Período 2: jan/2005 a dez/2013: } \\
I N F L_{z}=\beta_{0}+\beta_{1} \text { INFL } L_{t-1}+\beta_{z} D P E X_{t-1}+\beta_{3} D C A M B I O_{t-4}+\beta_{4} V O L_{t-1}+e_{z} \\
\quad \text { d) Modelo VAR(4) das variáveis } Y_{t}=(P T E X, D C A M B I O, V O L, B C, I N F L)^{s} \\
{\left[\begin{array}{ccc}
a_{11} & \cdots & a_{15} \\
\vdots & \ddots & \vdots \\
a_{51} & \cdots & a_{55}
\end{array}\right]\left[\begin{array}{c}
y_{1, t} \\
\vdots \\
y_{5, t}
\end{array}\right]} \\
\quad\left[\begin{array}{c}
v_{01} \\
\vdots \\
v_{05}
\end{array}\right]+\left[\begin{array}{ccc}
b_{11}^{1} & \cdots & b_{15}^{1} \\
\vdots & \ddots & \vdots \\
b_{51}^{1} & \cdots & b_{55}^{1}
\end{array}\right]\left[\begin{array}{c}
y_{1, t-1} \\
\vdots \\
y_{5, t-1}
\end{array}\right]+\cdots+\left[\begin{array}{ccc}
b_{11}^{p} & \cdots & b_{15}^{p} \\
\vdots & \ddots & \vdots \\
b_{51}^{p} & \cdots & b_{55}^{p}
\end{array}\right]\left[\begin{array}{c}
y_{1, t-p} \\
\vdots \\
y_{5, t-p}
\end{array}\right]+\left[\begin{array}{ccc}
b_{11} & \cdots & b_{15} \\
\vdots & \ddots & \vdots \\
b_{51} & \cdots & b_{55}
\end{array}\right]\left[\begin{array}{c}
u_{1, t} \\
\vdots \\
u_{5, t}
\end{array}\right] \\
\Rightarrow \quad A Y_{t}=v_{0}+B_{1} Y_{t-1}+\cdots+B_{p} Y_{t-4}+B u_{t}
\end{gathered}
$$

\subsubsection{Modelo VAR}

A forma reduzida de um modelo de vetores autorregressivos, $V A R(p)$, é dada por:

$$
Y_{t}=c_{0}+\Phi_{1} Y_{t-1}+\Phi_{2} Y_{t-2}+\cdots+\Phi_{p} Y_{t-p}+e_{t}
$$

onde: $\sigma_{0}-A^{-1} v_{0} ; \quad \Phi_{i}-A^{-1} D_{i} ; A e_{t}=B u_{t}$

A forma reduzida do VARpermite estimar consistentemente os parâmetros $c_{0}, \Phi_{i}, e_{t}$ por mínimos quadrados ordinários (MQO). Entretanto, o interesse está em analisar como o vetor $Y_{t}$ responde aos choques estruturais $u_{t}$. Uma forma de recuperar as inovações estruturais a partir das inovações da forma reduzida é estimar um modelo estrutural (SVAR) impondo restrições do tipo $a_{i j}=0$ à matriz $A$. A imposição de diferentes restrições irá resultar em diferentes funções de impulso-resposta, dependendo da magnitude da correlação entre os erros da forma reduzida ${ }^{\bullet}$. Apenas se todas as correlações entre os erros forem nulas as funções de impulso-resposta serão as mesmas, independentemente das restrições impostas. Empiricamente, uma "regra de bolso" para saber se modificações nas restrições serão relevantes é verificar as correlações entre os erros da forma reduzida $\left(\rho_{i j}\right)$. Caso $\left|p_{i j}\right|>0,2$ então as modificaçães na restrição $\alpha_{i j}$ correspondente resultarão em variações importantes na função de impulso-resposta ( $\mathrm{NDERS}$, 2008).

Os coeficientes da matriz $A$ determinam as relações contemporâneas entre as variáveis. O coeficiente $a_{i j}$ indica o efeito da variável $i$ sobre a variável $i$ no período $i$. Portanto identificam-se os pares de variáveis cujos erros apresentam correlação maior que | 0,2| e uma direção de causalidade deve então ser imposta para cada par de variável. A matriz $A$ de causalidades contemporâneas pode ser então estimada. Os coeficientes $\hat{a}_{i j}$ estimados que não forem estatisticamente significativos são supostos nulos e a matriz é reestimada quantas vezes forem necessárias até que todos os coeficientes estimados de $A$ sejam significativos.

O primeiro passo na estimação de um modelo VAR portanto, é a estimação da forma reduzida do modelo que deve atender a condição de estabilidade de que todos os autovalores do polinômio característico estejam dentro do círculo unitário e deve apresentar resíduos "bem comportados", isto é, que não apresentem autocorrelação.

Inicialmente o modelo reduzido foi estimado œm as variáveis INFL, DPEXT, DCAMBIO, BC e VOL para todo o período em análise, de janeiro de 2001 a dezembro de 2013. Os critérios 
de informação usuais BIC, $\mathrm{HQ}$ e AIC indicaram a seleção de 4 defasagens. Os testes de autocorrelação serial de Breusch-Godfrey e o de Portmanteau, cujos resultados estão no anexo, não rejeitaram a hipótese nula de ausência de autocorrelação serial a 10\% e o sistema atende às condições de estabilidade.

A análise da matriz de correlação dos resíduos indicou elevada correlação entre os resíduos das variáveis DCAMBIO e VOL (0.40) e DCAMBIO e PEXT (0.55). Dessa forma, foi necessário impor uma relação de causalidade contemporânea, isto é, no mesmo período $t$. Optou-se, portanto, por impor que DCAMBIO influencia contemporaneamente VOL e que DPEXT influencia contemporaneamente DCAMBIO.

\subsubsection{Modelo ARDL}

O modelo ARDL foi selecionado através da estratégia General-to-specific (GETS a partir de Hendry, Pagan and Saragan (1984) e Hendry (1987) e de acordo com a implementação dessa estratégia desenvolvida por Doornik e Hendry (2007). O objetivo da estratégia GETS é encontrar o modelo autoregressivo com defasagens distribuídas (ARDL) mais parcimonioso, com parâmetros estáveis e erros não autocorrelacionados, homocedáticos e normais.

O ponto de partida é a definição do modelo geral irrestrito na forma

$$
Y_{t}=\sum_{i=1}^{n} Y_{t-i}+\sum_{j=0}^{m} X_{t-j}+\varepsilon_{t}
$$

O segundo passo é a exclusão das defasagens com menor significância, isto é, as variáveis com os menores valores $t$ absolutos. A cada rodada de exclusão o modelo é reestimado. O segundo passo termina quando todas as variáveis que permanecerem no modelo forem estatisticamente significativas a um nível de confiança pré-estabelecido. Além disso cada modelo estimado é sujeito a uma série de testes de diagnóstico e quando um deles falha o modelo é rejeitado. Por fim, o critério de informação de Schwarz é utilizado para decidir entre os modelos restantes ${ }^{8}$.

Estimou-se o modelo geral irrestrito com cinco defasagens para cada uma das variáveis estacionárias INFL, BC, DPEXT, DCAMBIO e VOL, onde DPEXT é a primeira diferença da variável PEXT e DCAMBIO a primeira diferença da variável CAMBIO. Após os critérios descritos acima, o modelo a seguir foi selecionado. Devido a presença de heterocedasticidade nos resíduos, os erros padrão foram recalculados utilizando o estimador de Newey e West (1987).

\subsubsection{Testes de Paiz Unitária}

Foram realizados três testes de raiz unitária: o teste de Dickey-Fuller Aumentado (ADF), o teste de Zvot e Andrews (1992), e o teste de Lee e Strazicich (2003). O ADF é o teste padrão, amplamente utilizado para testar a estacionariedade das séries. No entanto, na presença de quebras estruturais, o teste dificilmente rejeita a hipótese nula de existência de raiz unitária. $\mathrm{O}$ teste de Zvot e Andrews identifica uma potencial quebra estrutural selecionando, endogenamente, o período da quebra onde a estatística de teste é menor e,

\footnotetext{
${ }^{8}$ Os testes de diagnósticos utilizados na seleção do modelo foram para autocorrelação dos resíduos Portmanteau e Durbin Watson, AROH teste para heterocedasticidade, teste de normalidade dos resíduos de Doornik and Hansen (1994), e o teste RESET de especificação de Ramsey (1969). Para mais detalhes ver Doornik (2009).
} 
consequentemente, a evidência é menos favorável à hipótese nula de presença de raiz unitária sem quebra estrutural. Por fim, o teste de Lee Strazicich realiza um procedimento semelhante ao de Zvot e Andrews, porém comporta quebra estrutural na hipótese nula e a possibilidade de existência de duas quebras estruturais na série. O Quadro 2 apresenta as hipóteses para os test es de raiz unitária e a Tabela 1 traz os resultados para as séries utilizadas.

Quadro 2-Hipóteses dos Testes de Raiz Unitária

\begin{tabular}{|c|c|c|}
\hline TESTE & $\mathrm{H}_{\mathbf{0}}$ & $\mathrm{H}_{1}$ \\
\hline $\mathrm{ADF}_{\tau}$ & Passeio Aleatório & Estacionária \\
\hline $\mathrm{ADF}_{\tau \mu}$ & $\begin{array}{l}\text { Passeio aleatório com } \\
\text { deslocamento }\end{array}$ & Estacionária \\
\hline$A D F_{\tau \tau}$ & $\begin{array}{lll}\text { Passeio } & \text { aleatório } & \text { com } \\
\text { tendência } & & \end{array}$ & Estacionária \\
\hline $\begin{array}{l}\text { Zvot e Andrews } \\
\text { (A) }\end{array}$ & $\begin{array}{l}\text { Passeio aleatório com } \\
\text { deslocamento (sem quebra) }\end{array}$ & $\begin{array}{l}\text { Estacionária, tendência, com uma } \\
\text { quebra no intercepto }\end{array}$ \\
\hline $\begin{array}{l}\text { Zvot e Andrews } \\
\text { (B) }\end{array}$ & $\begin{array}{l}\text { Passeio aleatório com } \\
\text { deslocamento (sem quebra) }\end{array}$ & $\begin{array}{l}\text { Estacionária, tendência com uma } \\
\text { quebra na inclinação }\end{array}$ \\
\hline $\begin{array}{l}\text { Zvot e Andrews } \\
\text { (C) }\end{array}$ & $\begin{array}{l}\text { Passeio aleatório com } \\
\text { deslocamento (sem quebra) }\end{array}$ & $\begin{array}{l}\text { Estacionária, tendência com uma } \\
\text { quebra no intercepto e na indinação }\end{array}$ \\
\hline Lee-Srazicich (A) & $\begin{array}{l}\text { Passeio aleatório com quebra } \\
\text { no nível }\end{array}$ & Estacionária com quebra no nível \\
\hline Lee-Strazicich (C) & $\begin{array}{l}\text { Passei aleatório com quebra no } \\
\text { nível e na tendência }\end{array}$ & $\begin{array}{l}\text { Estacionária com quebra no nível e na } \\
\text { tendência }\end{array}$ \\
\hline
\end{tabular}

Fonte: Eaboração Pópria (nov/2014). 
Tabela 1 - Resultados dos testes de raiz unitária

\begin{tabular}{|c|c|c|c|c|c|c|c|}
\hline TESTE & IPCA & INFL & $B C$ & PEXT & CAMBIO & EXPEC & VOL \\
\hline $\mathrm{ADF}_{\tau}$ & 4.35 & $-2.77^{\star * \star}$ & -1.40 & 0.78 & -0.37 & $-1.91^{*}$ & $-3.97^{* \star *}$ \\
\hline $\mathrm{ADF}_{-\tau \mu}$ & 0.41 & $-5.07^{\star \star \star}$ & $-3.18^{\star *}$ & -1.70 & -1.74 & $-4.60^{\star * *}$ & $-4.45^{\star \star \star}$ \\
\hline $\mathrm{ADF}_{\pi}$ & -1.61 & $-5.25^{\star * *}$ & $-3.25^{\star}$ & -2.95 & -2.28 & $-4.79^{* * *}$ & $-6.39^{* * *}$ \\
\hline \multirow{2}{*}{$\begin{array}{l}\text { Zvot-Andrews } \\
\text { (A) }\end{array}$} & -3.33 & $-6.23^{\star * \star}$ & -4.21 & -3.72 & -3.63 & $-5.417^{\star *}$ & $-7.26^{\star \star *}$ \\
\hline & mar 2006 & mar 2003L & fev 2004 & mai 2002 & mar 2005 & abr 2005 & abr 2003 \\
\hline \multirow{2}{*}{$\begin{array}{l}\text { Zvot-Andrews } \\
\text { (B) }\end{array}$} & -2.97 & $-5.75^{* * *}$ & $-4.87^{* *}$ & -3.46 & -3.58 & $-5.28^{* * *}$ & $-6.64^{* * *}$ \\
\hline & jun 2010 & mai 2006 & jun 2005 & set 2002 & dez2010 & set 2006 & dez 2004 \\
\hline \multirow{2}{*}{$\begin{array}{c}\text { Zvot-Andrews } \\
\text { (Q) }\end{array}$} & -2.96 & $-7.13^{\star \star \star}$ & $-4.95^{\star}$ & -4.04 & -3.55 & $-6.47^{\star \star \star}$ & $-9.30 * * *$ \\
\hline & fev 2010 & jan 2003 & dez 2006 & mar 2005 & jun 2010 & fev 2003 & out 2002 \\
\hline \multirow{2}{*}{$\begin{array}{l}\text { Lee-Srazicich } \\
\text { (A) (1 quebra) }\end{array}$} & -1.89 & $-5.06^{\star * *}$ & $-3.60^{\star}$ & -2.92 & -1.85 & $-6.21^{* \star *}$ & $-5.44^{\star * *}$ \\
\hline & jun 2003 ( 0.54 ) & mai $2005(0.04)$ & dez 2008 ( 0.01$)$ & jan $2003(0.00)$ & jan $2003(0.00)$ & mai $2004(0.55)$ & mai $2005(0.05)$ \\
\hline \multirow{3}{*}{$\begin{array}{l}\text { Lee-Strazicich } \\
\text { (C) (1 quebra) }\end{array}$} & -2.86 & $-6.63^{\star * \star}$ & $-6.15^{\star \star \star}$ & -3.67 & -3.01 & $-11.96^{\star \star *}$ & $-6.30^{\star \star \star}$ \\
\hline & dez2006 ( 0.94$)$ & mar $2003(0.91)$ & abr $2007(0.27)$ & mar $2005(0.02)$ & mar $2005(0.24)$ & jan $2003(0.00)$ & abr $2005(0.83)$ \\
\hline & $\operatorname{dez} 2006(0.14)$ & mar $2003(0.00)$ & abr 2007 ( 0.00$)$ & mar $2005(0.00)$ & mar $2005(0.00)$ & jan 2003 ( 0.56$)$ & abr $2005(0.00)$ \\
\hline \multirow{3}{*}{$\begin{array}{l}\text { Lee-Srazicich } \\
\text { (A) (2 quebras) }\end{array}$} & -2.09 & $-5.34^{\star * *}$ & $-4.16^{\star \star}$ & -3.18 & -1.93 & $-9.85^{\star * \star}$ & $-5.75^{\star \star *}$ \\
\hline & jun 2003 ( 0.51) & dez 2002 ( 0.02$)$ & dez 2007 ( 0.04$)$ & jan $2003(0.00)$ & jan $2003(0.00)$ & mai $2004(0.44)$ & nov $2002(0.05)$ \\
\hline & jun 2005 ( 0.55 ) & mai $2005(0.03)$ & dez 2009 ( 0.08$)$ & jun 2012 ( 0.00 ) & mar $2007(0.07)$ & mar $2009(0.70)$ & mai $2005(0.04)$ \\
\hline \multirow{5}{*}{$\begin{array}{l}\text { Lee-Strazicich } \\
\text { (C) (2 quebras) }\end{array}$} & -4.54 & $-6.68^{* * *}$ & $-9.30^{* * *}$ & -4.86 & -4.48 & $-11.91^{* * *}$ & $-7.03^{* * *}$ \\
\hline & jun 2003 ( 0.28 ) & fev 2003 ( 0.81) & mar 2006 ( 0.42) & jan $2003(0.00)$ & mar $2003(0.00)$ & jan 2003 ( 0.01$)$ & jul 2003 ( 0.07$)$ \\
\hline & jun 2003 ( 0.94) & fev $2003(0.00)$ & mar 2006 ( 0.08) & jan $2003(0.16)$ & mar $2003(0.00)$ & jan 2003 ( 0.73 ) & jul 2003 ( 0.79$)$ \\
\hline & nov 2009 ( 0.35$)$ & mai $2008(0.64)$ & nov $2010(0.00)$ & out $2010(0.14)$ & jul $2007(0.10)$ & jul 2009 ( 0.75$)$ & abr 2005 ( 0.71$)$ \\
\hline & nov 2009 ( 0.00$)$ & mai $2008(0.04)$ & nov $2010(0.00)$ & out $2010(0.00)$ & jul 2007 ( 0.33$)$ & jul 2009 ( 0.85 ) & abr $2005(0.00)$ \\
\hline
\end{tabular}

Notas: Número de defasagens selecionado pelo critério de Schwarz; p-valores das dummies de quebra, nível ou tendência, entre parênteses; $\left({ }^{*}\right),\left({ }^{* \star}\right)$, e $\left({ }^{* * \star}\right)$ indicam rejeição de $\mathrm{H}_{0}$ a 10\% ${ }^{*}$ ), 5\% $\left(^{* *}\right)$ e 1\%, respectivamente. Valores críticos em Zvot e Andrews (1992), Lee e Strazicich (2003); As especificações das hipóteses de cada teste encontram-se no Quadro 2.

Fonte: Eaboração Própria (nov/2014). 
De acordo com os resultados dos testes, passou-se a considerar as variáveis INF, BC, EXPECe VOL como estacionárias em I(0). Quando as séries são não-estacionárias, é necessário diferenciá-las quantas vezes forem necessárias até que se obtenham séries estacionárias, encontrando, desse modo, sua ordem de integração. Assim sendo, as variáveis IPCA, PEXT e CAMBIO foram consideradas como estacionárias em I(1), tendo em vista que os testes de raiz unitária da primeira diferença das séries DIPCA, DPEXT e DCAMBIO indicaram estacionariedade.

\subsubsection{Testes de Cointegração entre as Variáveis I(1)}

Dada a evidência de que as séries PEXT, CAMBIO e IPCA possuem raiz unitária, é possível verificar se existem uma ou mais relações de cointegração entre elas. Em outras palavras, essas variáveis são não-estacionárias e, portanto, possuem uma tendência estocástica. Se essa tendência for comum entre elas, é possível que existam combinações lineares dessas variáveis que sejam I(0). Neste caso, diz-se que as variáveis são cointegradas e que existe uma relação de equilíbrio de longo prazo entre elas (LUTKBOHL, 2005). Assim sendo, foram realizados cinco test es de cointegração.

O teste de Engle e Granger (1987) testa a hipótese nula de "não cointegração" em duas etapas. A primeira etapa estima o vetor de cointegração através de Mínimos Quadrados Ordinários (MQO) e, em seguida, é aplicado um teste ADF sobre os resíduos para testar a hipótese nula de que os resíduos possuem raiz unitária e, portanto, que as variáveis não cointegram. O teste de Gregory e Hansen (1996) é um procedimento em dois estágios, semelhante ao teste de Engle e Granger, que considera a possibilidade de uma quebra estrutural no vetor de coint egração, isto é, que a relação linear entre as variáveis possa ter se alterado em um ponto desconhecido do período. A quebra estrutural é modelada através da utilização de variáveis dummy e, similarmente ao teste de raiz unitária de Zvot e Andrews (1992), a estatística do teste é computada para todos os períodos e o menor valor é selecionado. O teste de Engle-Granger foi realizado com as especificações "com constante" (EG-drift) e "com constante e tendência" (EG-trend Os testes de Gregory-Hansen foram realizados nas versões "com quebra de nível" (GH-O), "com tendência determinística e quebra de nível” (GH-CT) e "com tendência e quebra no nível e elasticidades" (GH-CST).

Foi realizado também o chamado "Bounds Test" (Pesaran e Shin, 2001) auja hipótese nula é ausência de relação de longo prazo entre as variáveis em um contexto de ARDL $A$ estatística do teste, apresentada no anexo, não rejeita a hipótese nula, de forma que se considera que não há uma relação de cointegração entre as variáveis.

Dos testes realizados, apenas um indicou a existência de cointegração e a estimação do vetor de coint egração apresentou resultados não esperados, com sinal contrário para taxa de câmbio. Como os resultados não foram considerados conclusivos, admitiu-se que não há cointegração entre as variáveis, tendo em vista que essa estratégia é mais conservadora e segura, pois: i) ela está correta se realmente não existir cointegração entre as variáveis e ii) caso exista cointegração, o modelo œm variáveis diferenciadas mantém a consistência dos estimadores.

\section{Resultadose Discussão}

\subsection{Revisão de Literarura}

Nos últimos anos, tem crescido o volume de estudos que procuram analisar os impactos da globalização e dos fatores externos sobre a dinâmica dos preços domésticos. IMF (2006) 
investiga como a globalização afetou a inflação em países industrializados selecionados. Foi estimado um modelo de inflação, que se constitui em uma extensão da Curva de Phillips, com dados para o período de 1960-2004. A análise conclui que a globalização contribuiu para reduzir a sensibilidade da inflação a fatores domésticos, ao mesmo tempo que teve um efeito significativo sobre os preços relativos das economias industriais. Yakova (2007), através de uma estimação para o Reino Unido (1993-2005), utilizando uma abordagem bayesiana, aponta para um achatamento da Ourva de Phillips provocado pelo aumento da importância do setor externo para a explicação dos preços domésticos. Borio e Flardo (2006) estimam modelos de Ourva de Phillips para 16 países da OODE e os resultados apontam que o efeito da média ponderada dos fatores externos sobre a inflação é positivo, significativo e crescente. Mody e Onnsorge (2006), analisando dados sobre os países da União Europeia (2002-2005), fornecem evidências empíricas para a redução da sensibilidade da inflação aos condicionantes domésticos, provocada pela globalização. Wyne e Kersting (2007) também encontram evidências empíricas, nos Estados Unidos, para a hipótese de impactos positivos dos fatores externos sobre a inflação.

Para a economia brasileira, Araújo e Modenesi (2010b), fornecem um amplo conjunto de evidências empíricas, através da estimação de um modelo SVAR (1999-2010), de que o setor externo desemprenha um papel crucial no IPCA. Holland e Mori (2010) analisam os efeitos dos fatores externos sobre a inflação brasileira (1999 a 2008) e concluem que os resultados foram amplamente robustos e a favor da hipótese de que a globalização tem afetado o processo inflacionário doméstico. IPEA (2013), ao estimar a inflação para os preços monitorados, encontra a relevância da taxa de câmbio e da inflação de commodities para a explicação do seu comportamento. Martinez e Cerqueira (2011) discutem os determinantes da inflação brasileira para o período 2000-2009 e apresentam resultados, através de um modelo baseado no método da função de transferência, que apontam para a importância dos fatores externos na determinação dos preços domésticos. Schwartzman (2006) faz estimativas de uma Ourva de Phillips reduzida para os preços comercializáveis, não comercializáveis e monitorados. Os resultados mostram que a taxa de câmbio tem impacto direto nos bens comercializáveis. Tombini e Alves (2006) estimam uma Ourva de Phillips híbrida para a economia brasileira (1999 e a 2006) e chegam a conclusão de que os preços livres respondem à inflação passada, à inflação esperada e ao repasse cambial.

A literatura que trata dos determinantes da inflação brasileira é ampla e apresenta uma diversidade de métodos e resultados. Todavia, assim como para os países industrializados, para a economia brasileira, é possível afirmar que há um certo consenso sobre a importância dosfatores externos para a explicação do processo inflacionário brasileiro, principalmente após as mudanças macroeconômicas e institucionais ocorridas ao longo dos anos 1990 e 2000.

\subsection{Pesultados do Modelo ARDL}

Na estimação por ARDL o saldo da balança comercial não se mostrou estatisticamente significante para explicar o comportamento do IPCA, tendo sido, então, excluído do modelo. Esse resultado endossa a ideia de que a influência do setor externo sobre os preços domésticos se dá, predominantemente, at ravés do canal de custos e não pela via da demanda. O resultado se manteve o mesmo quando a estimação foi feita nos dois períodos indicados anteriormente (jan/2001 a dez/2004 e jan/2005 a dez/2013), como pode ser visto nas tabelas 11 e 12 do anexo. 
Tabela 2 - Modelo ARDL - jan/2001 a dez $2013^{9}$

\begin{tabular}{|c|c|c|c|c|c|c|}
\hline & Coeficiente & Ero-Padrão & HACSE & t-HACSE & t-prob & R2 parcial \\
\hline INPL_1 & 0.45 & 0.05 & 0.05 & 8.39 & 0.00 & 0.33 \\
\hline Constant & 0.20 & 0.03 & 0.03 & 6.06 & 0.00 & 0.21 \\
\hline DPEXT_1 & 0.02 & 0.00 & 0.00 & 4.65 & 0.00 & 0.13 \\
\hline DPEXT_3 & 0.02 & 0.01 & 0.01 & 3.18 & 0.00 & 0.07 \\
\hline DCAMBIO_2 & 0.68 & 0.21 & 0.25 & 2.69 & 0.01 & 0.05 \\
\hline DCAMBIO_3 & -0.74 & 0.24 & 0.22 & -3.36 & 0.00 & 0.07 \\
\hline $\mathrm{VOL}_{2} 2$ & 14.78 & 3.01 & 3.94 & 3.75 & 0.00 & 0.09 \\
\hline $\mathrm{VOL}_{-} 4$ & 17.36 & 3.18 & 2.38 & 7.30 & 0.00 & 0.27 \\
\hline \multicolumn{7}{|l|}{$\sigma=0,21$} \\
\hline \multicolumn{7}{|l|}{$F^{2}=0,73$} \\
\hline \multicolumn{7}{|c|}{$F^{2}$ Ajustado $=0,72$} \\
\hline \multicolumn{7}{|c|}{ Teste AR1-7 : F(7,135) =0.9112 [0.4549] } \\
\hline \multicolumn{7}{|c|}{ Teste AROH 1-7: $\mathrm{F}(7,136)=1.9741$ [0.0629] } \\
\hline \multicolumn{7}{|c|}{ Teste de Normalidade $\quad$ Chi^$^{\wedge} 2(2)=3.5676[0.1680]$} \\
\hline \multicolumn{7}{|c|}{ Teste de heterocedasticidade: $\quad F(14,135)=1.9085[0.0305]^{*}$} \\
\hline \multicolumn{7}{|l|}{ RSS $=6.21$} \\
\hline \multicolumn{7}{|c|}{$F(7,142)=55.95[0.000] * *$} \\
\hline \multicolumn{7}{|c|}{ Razão de Verossimilhança = 26.03} \\
\hline \multicolumn{7}{|c|}{ Nota: * Sgnificativo a $1 \%$ ** Sgnificativo a $5 \%$ *** Sgnificativo a $10 \%$} \\
\hline
\end{tabular}

Fonte: Eaboração Pópria (nov/2014).

Os resultados para as variáveis do componente autônomo - taxa de câmbio e preços externos - permitem inferir que esse canal foi importante para a trajetória do IPCA entre 2001 e 2013. Na estimação para o período de jan/2001 a dez/2004, o modelo explica bem o comportamento da inflação, tendo em vista o valor do $R^{2}(0,78)$. A taxa de câmbio explicou melhor o comportamento do IPCA, enquanto a influência dos preços externos não se mostrou muito relevante. Para o segundo período, entretanto, o resultado foi o contrário: a influência dos preços externos foi mais forte que a taxa de câmbio. Esse resultado vai ao encontro do que foi sugerido por Braga (2013): na primeira metade da década de 2000, as pressões cambiais foram mais relevantes para explicar a inflação doméstica, ao passo que, na segunda metade da década, os preços externos exerceram pressões significativas no IPCA.

Para o segundo período, o modelo estimado é menos aderente à inflação observada, uma vez que o $R^{2}$ é da ordem de 0,48 . Isto não invalida a importância dos fatores externos para a inflação brasileira no período 2005-2013 - embora menor que o do período anterior,

\footnotetext{
${ }^{9}$ Os modelos originalmente estimados apresentaram heterocedasticidade nos resíduos. Como na presença de heterocedasticidade as inferências estatísticas são viesadas e as estatísticas t são inadequadas, o modelo foi reestimado utilizando a correção de erros-padrão robustos a heterocedasticidade e autocorrelação (HACSE), de acordo com Newey e West (1987) e Andrews (1991). Os erros padrão e as estatísticas t robustos foram apresentadas na tabela.
} 
este $R^{2}$ não é baixo - mas apenas sugere a emergência de novos fatores explicativos da dinâmica inflacionária brasileira como, por exemplo, a inflação no setor de serviços ${ }^{9}$.

Por fim, no que tange ao componente de realimentação, a volatilidade da taxa de câmbio foi importante para explicar o IPCA, tanto no modelo estimado para o período completo, quanto para os dois subperíodos. Entretanto, no segundo período a volatilidade esteve inversamente relacionada œm o IPCA, indicando que não atuou no sentido de acentuar, mas sim de atenuar a inflação. Entre 2001 e 2013, uma variação de uma unidade na volatilidade cambial impactou o coeficiente estimado para a inflação em 14,78 e 17,36 para duas e quatro defasagens, respectivamente. A importância dessa variável pode estar sendo superdimensionada, pelo peso dos anos 2001-2003, quando a volatilidade cambial foi alta, em meio à tendência de depreciação da taxa de câmbio.

\subsection{Resultados do Modelo SVAR}

Com base no modelo SVAR foram analisados os seguintes aspectos do comportamento do IPCA: œeficientes de repasse, decomposição da variância e funções impulso-resposta. De forma geral, os resultados dos modelos ARDL e SVAR são semelhantes, o que robustece os resultados encontrados e aumenta a confiança de que a síntese obtida com as estimações seja verossímil.

Como a hipótese adotada no modelo foi a de que as expectativas inflacionárias são, em parte, função da volatilidade cambial (expectativas $=f$ (volatilidade cambial)), foram realizados testes de causalidade de Granger entre essas variáveis. A variável $X$ "causa" $Y$ no sentido de Granger quando as defasagens de Xajudam a prever Y (Granger, 1969), ou seja, os coeficientes das defasagens de $X \propto$ ntra $Y$ são estatisticamente significativos. A hipótese nula neste caso é que as defasagens da variável "não Granger-causa" a variável dependente. A rejeição da hipótese nula implica, portanto, em causalidade de Granger.

Como ambas as variáveis (expectativas e volatilidade cambial) são estacionárias, o teste de causalidade de Granger pode ser realizado normalmente sem necessidade de correção no número de defasagens do VAR de origem determinadas pelo critério de informação de Schwarz ${ }^{9}$ A Tabela 3 apresenta os resultados para o teste realizado.

Tabela3 - Testes de Causalidade de Granger

\begin{tabular}{|c|c|c|c|}
\hline & $\chi^{2}$ & df & Prob. \\
\hline $\begin{array}{c}\text { Variável Dependente: } \\
\text { VOL EXPEC }\end{array}$ & 29.18633 & 6 & 0.0001 \\
\hline $\begin{array}{c}\text { Variável Dependente: } \\
\text { EXPEC VOL }\end{array}$ & 62.35385 & 6 & 0.0000 \\
\hline
\end{tabular}

Fonte: Eaboração Própria (nov/ 2014).

Como a hipótese nula ("não Granger causa") pode ser rejeitada para os dois testes, conclui-se que a causalidade se verifica nas duas direções, ou seja, EXPEC "Granger-causa” VOL e VOL "Granger-causa" EXPEC. Assim sendo, o resultado do teste pode ser utilizado para

\footnotetext{
${ }^{10}$ Sobre o comportamento do setor de serviços e sua influência no IPCA, ver, por exemplo, Braga (2013).

${ }_{11}$ Os resultados dos testes, entretanto, não se alteram quando o número de defasagens é alterado. Na tabela 7 do anexo estão os resultados do teste para de 1 a 5 defasagens.
} 
validar a hipótese antes sugerida, de que a volatilidade cambial é um fator explicativo das expectativas inflacionárias.

\subsubsection{Coeficientes de Repasse}

O cálculo do repasse para a inflação pode ser realizado a partir das funçães de impulsoresposta estimadas pelo modelo VAR Conforme sugerido por McCarthy (2000), e estimado para o Brasil por Belaisch (2003) e Araújo e Modenesi (2010b), tem-se:

$$
H_{t, t+j}=\left(\frac{\Sigma \Delta Y_{t_{s} t+j}}{\Sigma \Delta X_{t_{t} t+j}}\right) \cdot 100
$$

onde $Y$ é a inflação e $X$ a variável para a qual se está medindo o repasse.

O repasse é calculado após um choque no câmbio no modelo SVAR, dividindo-se a variação acumulada do IPCA (após j meses) pela variação acumulada da variável em questão (apósj meses). A Tabela 4 mostra os coeficientes de repasse dos choques nos preços externos, na taxa de câmbio, na volatilidade cambial e no saldo da balança comercial para o IPCA.

Tabela 4-Coeficientes de Repasse - período: jan/२001 a dez/२०1૩

\begin{tabular}{|c|c|c|c|c|}
\hline Período & Repasse DPEXT & Repasse DCAMBIO & Repasse VOL & Repasse BC \\
\hline 1 & 0.00 & 0.00 & 0.00 & 0.00 \\
\hline 2 & 0.02 & 0.01 & -2.65 & 0.00 \\
\hline 3 & 0.04 & 0.51 & 11.99 & 0.00 \\
\hline 4 & 0.06 & 0.56 & 22.58 & 0.00 \\
\hline 5 & 0.08 & 0.89 & 37.93 & 0.00 \\
\hline 6 & 0.10 & 1.28 & 49.81 & 0.00 \\
\hline 7 & 0.12 & 1.83 & 53.79 & 0.00 \\
\hline 8 & 0.13 & 2.15 & 57.78 & 0.00 \\
\hline 9 & 0.15 & 2.51 & 62.89 & 0.00 \\
\hline 10 & 0.16 & 2.83 & 63.44 & 0.00 \\
\hline 11 & 0.16 & 3.09 & 62.80 & 0.00 \\
\hline 12 & 0.16 & 3.29 & 63.63 & 0.00 \\
\hline
\end{tabular}

Fonte: Baboração Pópria (nov/2014).

Pelos resultados encontrados, um choque na balança comercial não apresenta efeitos significativos sobre o IPCA. Isso reforça o resultado obtido no modelo ARDL, de que o impacto do setor externo sobre os preços domésticos no Brasil não se dá, predominantemente, pelo canal da demanda, mas sim pelo canal dos custos, através dos componentes autônomo e de realimentação.

Quando se analisa o componente autônomo, tanto o repasse dos preços externos quanto o da taxa de câmbio são crescentes ao longo do tempo, sendo o segundo, claramente, 
mais importante. Ao final de 12 meses, o aumento de uma unidade nos preços externos e na taxa de câmbio provoca aumentos de 0,16 e 3,29, respectivamente, no IPCA.

Da mesma forma, a volatilidade cambial apresenta relevância considerável para explicar a dinâmica do IPCA: ao final de 12 meses, o choque causado pelo aumento de uma unidade nessa variável, provoca um aumento de 63,63 unidades na inflação. Como sugerido, um dos canais pelos quais a volatilidade cambial impacta a inflação, na nova configuração de maior grau de abertura financeira, é por meio da sua influência na formação das expectativas inflacionárias. O teste de causalidade de Granger mostrou que existe uma estreita relação entre essas variáveis, que se causam mutuamente. Portanto, é possível afirmar que, em algum grau, a volatilidade da taxa de câmbio contribuiu para explicar os movimentos do IPCA no período 2001-13, pela via das expectativas de inflação.

\subsubsection{Decomposição da Variância}

A análise de decomposição de variância permite verificar a participação relativa de cada variável na explicação da variância de outra variável do modelo. Nesse caso, permite avaliar a importância relativa dos preços externos, da taxa de câmbio, da volatilidade cambial, do saldo da balança comercial e da própria inflação sobre o IPCA. A Tabela 5 apresenta a decomposição da variância do IPCA, entre 2001 e 2013.

Tabela 5 - Decomposição da Variância - período: jan/2001 a dez/ २०13

\begin{tabular}{|c|c|c|c|c|c|c|}
\hline Período & SE & DPEXT & DCAMBIO & VOL & BC & INFL \\
\hline 1 & 0.208565 & 0.000000 & 0.000000 & 0.000000 & 0.000000 & 100.0000 \\
\hline 2 & 0.240144 & 8.512440 & 0.000975 & 0.424661 & 0.568242 & 90.49368 \\
\hline 3 & 0.285988 & 19.18045 & 3.658875 & 11.43230 & 1.900632 & 63.82774 \\
\hline 4 & 0.317074 & 24.02159 & 3.068587 & 17.34954 & 3.400591 & 52.15970 \\
\hline 5 & 0.363582 & 24.74012 & 3.457276 & 29.12343 & 2.589940 & 40.08923 \\
\hline 6 & 0.386331 & 24.59654 & 4.833420 & 32.62248 & 2.337775 & 35.60978 \\
\hline 7 & 0.397001 & 23.87014 & 6.421227 & 33.31042 & 2.595871 & 33.80233 \\
\hline 8 & 0.403202 & 23.41118 & 7.052555 & 34.04299 & 2.719613 & 32.77366 \\
\hline 9 & 0.407764 & 22.93368 & 7.698691 & 34.24095 & 3.026375 & 32.10031 \\
\hline 10 & 0.409897 & 22.70468 & 8.122433 & 33.90830 & 3.459632 & 31.80495 \\
\hline 11 & 0.411435 & 22.57556 & 8.278508 & 33.68604 & 3.877146 & 31.58275 \\
\hline 12 & 0.412792 & 22.49154 & 8.344655 & 33.50874 & 4.269714 & 31.38535 \\
\hline
\end{tabular}

Fonte: Eaboração Própria (nov/2014).

Nos primeiros meses, a maior parte da variância da inflação é explicada pela própria inflação, o que confirma a importância da inércia inflacionária no Brasil. Ao final de 12 meses aproximadamente $32 \%$ da variância do IPCA é explicada pelo próprio IPCA. Esse valor foi de 
$34,4 \%$ para o período de jan/2001 a dez/2004 e de 75,8\% para o período de jan/2005 a dez/2013, conforme tabelas 13 e 14 do anexo.

Embora medidas de desindexação tenham sido adotadas desde meados dos anos 1990 no Brasil, e ampliadas a partir de 2004, a análise da decomposição da variância, para o período de jan/2005 a dez/2013, sugere que o peso da inércia aumentou, já que, nesse período, ao final de 12 meses, 75,8\% da variância do IPCA é explicada pelo próprio IPCA. Esse resultado pode estar associado ao aumento do peso do setor de serviços na explicação do IPCA a partir de 2010, principalmente daqueles de preços não monitorados. Como observam MATINEZ e $\operatorname{BRAGA}(2012$, p. 6),

"os serviços livres são a única categoria do IPCA que não sofre influência direta nem dos preços das commodities nem da taxa de câmbio, mas predominantemente de seu próprio passado, sugerindo comportamento fortemente inercial."

O comportamento dos preços nesse setor é fortemente influenciado pela variação salarial e, a partir de meados de 2005, esta superou a inflação (tendo o salário mínimo apresentado ganho real superior ao do salário médio). Assim, é bastante provável que essa conjunção de fatores tenha contribuído para aumentar o peso do componente inercial da inflação no período 2005-2013 (BRAGA, 2013). Além disso, o baixo valor do Pf no modelo ARDL estimado para o segundo período (tabela 8) sugere que as variáveis indicadas não são suficientes para explicar a inflação. A ausência de outras variáveis relevantes pode, então, estar sendo captada pela inércia, isto é, no período t-1 uma variável não observável pode estar influenciando a dinâmica dos preços e produzindo inflação no período t. Os resultados encontrados para essa componente são consistentes com a evolução da inflação brasileira- no período analisado, ainda fortemente influenciada pela inércia inflacionária.

Ainda analisando o componente de realimentação, observa-se a importância crescente da volatilidade cambial para explicar a variância do IPCA. Ao final de 12 meses, aproximadamente $33 \%$ da variância da inflação é explicada pela volatilidade da taxa de câmbio. Esse valor foi de 20,8\% para o período de jan/2001 a dez/2004 e de 9,2\% para o período de jan/2005 a dez/2013. A queda aqui não é no componente de realimentação como um todo, mas apenas na volatilidade cambial. No primeiro período, especialmente por influência dos anos 2001 e 2002, a volatilidade exerce maior impacto no IPCA. Como uma das hipóteses aqui consideradas é que a volatilidade do câmbio afeta o IPCA através das expectativas inflacionárias, esse resultado reforça a importância do canal das expectativas para a explicação da dinâmica inflacionária brasileira Juntas, as variáveis do componente de realimentação - inércia e expectativas (estas expressas como função da volatilidade cambial) explicam, ao longo de 12 meses, cerca de 62\% da variância do IPCA.

O componente de demanda respondeu, ao final de 12 meses, por apenas 4,3\% da variação do IPCA, confirmando o resultado do teste anterior (de baixa relevância deste componente). Nos modelos estimados para os períodos de jan/2001 a dez/2004 e jan/2005 a dez/2013, esse valor foi de 9,9\% 3,1\%, respectivamente.

No que concerne ao componente autônomo os preços externos contribuíram mais significativamente para a evolução do IPCA do que a taxa de câmbio, no período 2001-2013. Este resultado, provavelmente, reflete uma tendência da pauta de exportações brasileira nesse período, de especialização em direção aos produtos primários. Ao final de 12 meses, o preço das commodities explicou $23,5 \%$ da variância do IPCA, enquanto que para a taxa de câmbio esse valor foi de $8,3 \%$ Nos modelos estimados para os períodos de jan/2001 a dez/2004 e jan/2005 a dez/2013, esse valor foi de 30,6\% e 8,9\% para os preços externos e de 4,2\% e 2,8\% para a taxa de câmbio, respectivamente. Juntas, entre 2001 e 2013, as variáveis 
do componente autônomo respondem por cerca de 30,8\% da variância do IPCA. Se, entretanto, a volatilidade da taxa de câmbio for adicionada a esse grupo de variáveis, o valor chega a aproximadamente $64,3 \%$, isto é, quase dois terços da inflação brasileira nesse período são explicados, direta ou indiretamente, pelos condicionantes externos. A análise da decomposição da variância do IPCA, portanto, soma-se às evidencias já apresentadas para ressaltar o alto peso dosfatores externos na evolução da inflação brasileira.

\subsubsection{Funções de Impulso Pesposta}

Em seguida, são analisadas as funções impulso-resposta da inflação a um choque, respectivamente, em: preços externos, taxa de câmbio, volatilidade cambial e saldo da balança comercial. A figura 1 mostra as funções de impulso-resposta, para o período 2001-13, decorrentes de um choque de um desvio padrão das variáveis citadas, onde: shock1=DPEXT; shock2=DCAMBIO; shock3=VOLe shock4=BC.

Figura1 - Resposta do IPCA a um choque em: preços externos, câmbio, volatilidade cambial e balança comercial (VAR): 2001-2013 - Fatoração Estrutural.
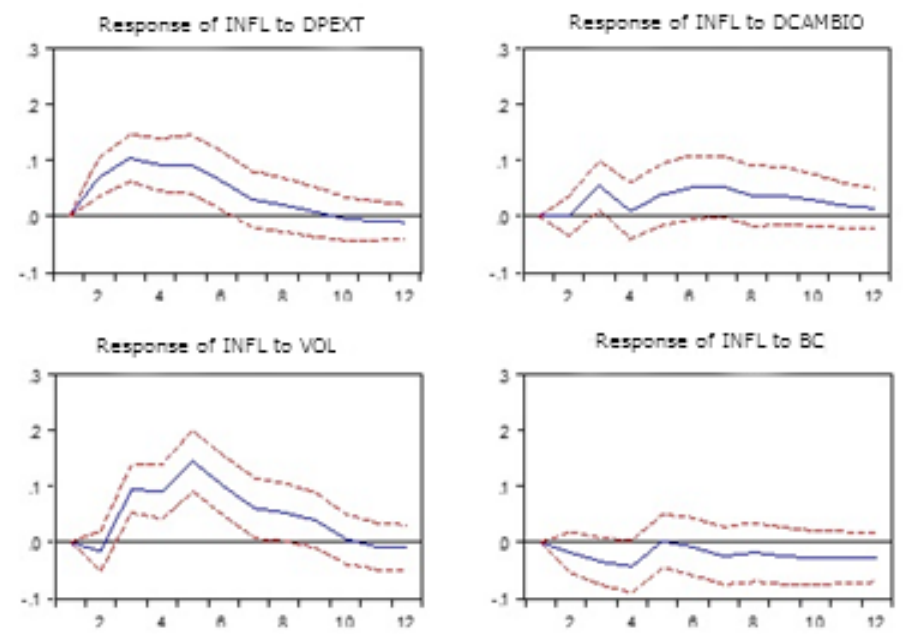

Fonte: Eaboração Própria (nov/2014).

Como era de se esperar, o efeito de um choque na balança comercial sobre o IPCA apresenta fraca intensidade, evidenciando a baixa relevância do componente de demanda no período em análise. Esse resultado não se altera para os períodos de jan/2001 a dez/2004 e jan/2005 a dez/2013 (ver figuras 2 e 3 do anexo).

Dentre os choques analisados, o da volatilidade cambial é consideravelmente mais intenso que os choques nos preços externos e na taxa de câmbio, embora esses também sejam relevantes e significativos na dinâmica do IPCA. No período entre jan/2001 e dez $2004^{12}$, esse resultado se mantém, o que não acontece no período seguinte, jan/2005 a dez/2013, quando um choque na volatilidade cambial apresenta impactos negativos no IPCA.

Em momentos de elevada volatilidade cambial, como, por exemplo, no período entre janeiro de 2001 e janeiro de 2002, verificou-se uma deterioração nas expectativas

\footnotetext{
${ }^{12}$ As funções impulso-resposta para os modelos estimados para os períodos de jan/2001 a dez/2004 e jan/2005 a dez/2013 encontram-se anexas ao artigo.
} 
inflacionárias, elevando o peso destas e, indiretamente, da volatilidade cambial na inflação. A partir de 2004, as expectativas de inflação se moveram com mais frequência e intensidade do que a volatilidade cambial. Isto sugere que, entre 2004 e 2013, houve uma redução no peso dessa variável na formação das expectativas inflacionárias, o que explica a redução de seu peso também na inflação do período.

Oresultado encontrado para a relação entre essas duas variáveis (volatilidade cambial e expectativas inflacionárias) é relevante, na medida em que sugere, assim como na relação entre taxa de câmbio e inflação, a existência de um repasse assimétrico. Em outras palavras, quando a volatilidade da taxa câmbio está elevada, seu impacto sobre as expectativas de inflação é mais significativo. Por outro lado, quando a volatilidade do câmbio está baixa, sua influência sobre as expectativas inflacionárias é menor e outros fatores são mais relevantes para explicar o comportamento dessa variável. Essa conclusão é importante, pois sugere que, ao contrário do que propõem as teorias ortodoxas, dominantes no mercado, a inflação, no Brasil, não tem sido, predominantemente, sustentada por expectativas inflacionárias, mas sim por fatores objetivos de custo, com importância relevante das pressões de custo advindas do setor externo.

Combinando a função impulso-resposta com a análise da decomposição da variância, o componente de realimentação apresenta importância significativa no comportamento do IPCA, tendo em vista: i) a resposta do IPCA a um choque na volatilidade da taxa de câmbio e ii) o fato de, ao longo de 12 meses, parte considerável da inflação ser explicada por sua própria variância, o que pode ser interpretado como uma medida da inércia inflacionária.

Por fim, o componente autônomo, mostrou-se claramente importante na evolução do IPCA. A inflação responde de forma positiva tanto a um choque nos preços externos quanto na taxa de câmbio, tendo o primeiro, efeitos mais intensos sobre o IPCA. Entretanto, para a taxa de câmbio, o choque é mais significativo no primeiro período (jan/2001 e dez/2004). Para os preços externos, o impacto de um choque é positivo nos dois períodos (jan/2001 e dez/2004 e jan/2005 e dez/2013). Essa constatação confirma a hipótese de que os condicionantes externos assumiram um papel crucial na dinâmica da inflação brasileira, no período compreendido entre 2001 e 2013.

\section{Sumário e Conclusões}

Partindo da hipótese de que o processo internacional de liberalização comercial e financeira dos anos 1990 tornou a inflação doméstica, em todos os países, mais sensível às variáveis externas, este artigo estimou uma equação de inflação, visando avaliar o peso dessas variáveis na inflação brasileira no período 2001-2013. O modelo de inflação proposto por Smonsen (1970), que serviu de base às estimações, associa a inflação a três grupos de variáveis: o componente de demanda, o componente de realiment ação e o componente autônomo.

No que concerne ao componente de demanda, o efeito do setor externo sobre os preços domésticos foi analisado através do saldo da balança comercial. De maneira geral, a análise mostrou que o saldo da balança comercial não exerce influência significativa sobre o IPCA. A resposta do IPCA a um choque na balança comercial não foi tão expressiva, quando comparada a um choque nas demais variáveis. Além disso, o saldo da balança comercial foi responsável por apenas $4,3 \%$ da variância da inflação. Por fim, o coeficiente de repasse da balança comercial para o IPCA confirma o que foi mostrado nas outras análises: o saldo da balança comercial não tem impactos significativos sobre a inflação, entre 2001 e 2013.

O componente de realimentação apresentou resultados significativos. Primeiro, como já era esperado, a inércia mostrou-se um importante fator explicativo da inflação. De acordo 
com a decomposição da variância, entre 2001 e 2013, aproximadamente 31,4\% do IPCA foi explicado por sua própria variância. Esse valor foi de 34,4\% para o período de jan/2001 a dez/2004 e de 75,8\% para o período de jan/2005 a dez/2013. Embora tenham sido adotadas novas medidas de desindexação, ao longo dos anos 2000 , os resultados da análise da decomposição da variância, para o período de jan/2005 a dez/2013, sugerem que o peso da inércia aumentou. Como já observado, esse resultado pode estar associado ao aumento do peso do setor de serviços, de preços livres, para a explicação do IPCA.

Os resultados das estimações para a volatilidade cambial foram: i) a volatilidade da taxa de câmbio foi importante para explicar o IPCA, tanto no modelo estimado via SVARcomo na estimação feita via ARDL, embora tenha sido mais significativa no primeiro período quando sua variância explicou $20,8 \%$ da inflação e ii) essa variável apresenta forte correlação com as expectativas de inflação e as mesmas se causam, mutuamente, no sentido de Granger.

Ocomponente autônomo - que inclui as pressões de custo sobre os preços - mostrouse, como era de se esperar, bastante significativo para explicar a evolução do IPCA. Os preços externos exerceram influência relevante sobre a inflação brasileira. Nos dois modelos estimados, essa variável mostrou-se significativa e seu impacto no IPCA foi mais intenso no subperíodo de jan/2005 a dez/2013, quando se verifica uma forte tendência de elevação dos preços das commodities nos mercados internacionais. O resultado do coeficiente dos preços externos, no modelo ARDL, menor que o da taxa de câmbio, pode estar indicando, como sugere Braga (2013), que a inflação importada não é inteiramente dominada pelo preço das commodities, sendo influenciada também pelo preço dos produtos manufaturados.

Como mostrou a análise das funções impulso-resposta, nos dois subperíodos e no modelo estimado para o período completo, a resposta do IPCA a um choque nos preços externos é positiva, principalmente nos primeiros meses. Além disso, pela decomposição da variância, mostrou-se que os preços externos tiveram impacto maior que a variação cambial sobre a evolução do IPCA. Por fim, a tendência crescente do œeficiente de repasse dos preços externos para a inflação doméstica endossou a importância dessa variável.

A taxa de câmbio atuou de forma distinta entre 2001 e 2013, ora arrefecendo, ora acentuando as pressões dos preços das commodities sobre os preços domésticos. No modelo ARDL, o coeficiente do câmbio foi significativo nos dois subperíodos e no período completo. A partir de 2003, verificou-se uma apreciação da taxa de câmbio que contribuiu para filtrar os efeitos dos preços externos. No modelo para o primeiro período, a função impulso resposta evidenciou a importância de um choque de câmbio para o IPCA. Já no segundo período a função mostrou que a taxa de câmbio contribuiu para arrefecer as pressões geradas pelo aumento do preço das commodities. A decomposição da variância mostrou ainda que a taxa de câmbio foi mais importante para explicar a inflação do primeiro período. Por fim, o coeficiente de repasse de um choque no câmbio para os preços apresentou trajetória crescente.

Em suma, os resultados da análise parecem indicar que, ao contrário do discurso dominante, a inflação recente no Brasil não tem sido sustentada por fatores de natureza conjuntural, como as expectativas inflacionárias ou o crescimento da demanda. No período 2001-2013, fatores estruturais de custo se mostraram mais importantes nesse processo, tendo peso relevante as pressões do setor externo. 


\section{RP苗代aS}

Araújo, E; Modenesi, A. M. (2010b) "A Importância do Setor Externo na Evolução do IPCA (1999-2010): uma análise com base em um modelo SVAR" XXVIII Encontro Nacional de Eoonomia, Salvador.

Azevedo, A. F. Z; Portugal, M. S (1998)."Abertura comercial brasileira e instabilidade da demanda de importações”. Nova Economia, 8(1), p. 37-63.

Belaisch, A. (2003). “Exchange rate pass-through in Brazil”. IMFWorking Papers, n 141.

Borio, C; Flardo, A. (2006).Globalization and inflation: New cross-country evidence on the global determinants of domestic inflation. Banco Mundial: Washington.

Braga, J. (2013). "A inflação brasileira na década de 2000 e a importância das políticas não monetárias de controle." Economia e Sociedade, 22(3), p. 697-727.

Doornik, J. (2009). "Autometrics". In: J Castle; N. Shephard, N. The Methodology and Practice of Econometrics: A Festschrift in Honour of David F. Hendry. Oxford University Press: Oxford.

Enders, W. (2008). Applied econometric time series. John Wiley\&Sons: New York. 3. ed.

Engle, F.; Granger, C. (1987) "Co-integration and error correction: representation, estimation and testing." Econometrica, 55, p. 251-276.

Freitas, F. N. P.; Dweck, E (2013). "The Pattern of Economic Growth of the Brazilian Economy 1970-2005: a demand-led growth perspective." In: E Levrero; A. Palumboand; A Stirati. Sraffa and the Peconstruction of Eoonomic. Palgrave Macmillan: New York, v. 2, p. 157-198.

Fritsch, W.; Franco, G H. B. (1991)."Política Comercial de Competição do Investimento Estrangeiro: análise da experiência recente e proposta de reforma"., Texto para Discussão, 63, Fundação de Comércio Exterior: Ro de laneiro.

Fuhrer, J. C. "Inflation Persistence". (2009). Federal Reserve Bank Working Paper, 09-14. Boston.

Granger, C. (1969). "Investigating causal relations by econometric models and cross-spectral methods". Econometrica37, p. 424-438.

Greene, W. (2003). Econometric Analysis. Macmillan: New York, 6. ed.

Hendry, D. F. (1987). "Econometric methodology: a personal perspective". In: T. Bewley (ed.)Advances in econometrics. Cambridge University Press: Cambridge, Cap. 10.

Hendry, D. F.; Pagan, A. R; Sargan, J D. (1984). "Dynamic Specíficatíon”. In: Z Giliches; M. Intriligator (eds.) Handbook of Econometrícs. North-Holland: Amsterdam, v. 2.

Holland, M.; Mori, R (2010)."Dinâmica da inflação no Brasil e os efeitos globais”. Revista da ANPEC 11, p. 649-679.

IMF. (2006). "How has globalization affected inflation". World Economic Outlook,Washington.

IPEA.(2013). "A dinâmica dos preços administrados". Carta de Conjuntura, 18,Instituto de Pesquisa Econômica Aplicada: Brasília.

Kume, H.; Patricio, ل A. (1987). "A Reforma Aduaneira proposta pela CPA: um primeiro passo para a formação de uma política tarifária”. Texto para Discussão Interna, 10,Fundação Centro de Estudos do Comércio Exterior: Ro de Janeiro. 
Kume, H.; Pani, G.; Souza, C. F. B. (2003). "A política brasileira de importação no período 19871998: descrição e avaliação”. In: C. Corseuil; H. Kume. A abertura comercial brasileira nos anos 1990: impactos sobre emprego e salário. MTEe IPEA: Ro de Janeiro.

Lee, J; Srazicich, M. C. (2003).“Minimum LM unit root test with two structural breaks". Peview of Economics and Statistics, 63, p. 1082-1089.

Lopes, F. L (1984a).“Só um Choque Heterodoxo pode Derrubar a Inflação”. Economia em Perspectiva. Conselho Regional de Economia de São Paulo: São Paulo.

Lutkepohl, H. (2005).A new introduction to multiple time series analysis. Springer Verlag: Berlim.

Martinez, T.; Braga, J. (2012). "Orescimento liderado pelos salários, política monetária e inflação no Brasil”. V Encontro Internacional da Associação Keynesiana Brasileira, São Paulo.

Martinez, T. S; Cerqueira, V. S (2011). "Estrutura da Inflação Brasileira: determinantes e desagregação do IPCA". Texto para Discussão, 1634, Instituto de Pesquisa Econômica Aplicada: Ro de Janeiro.

Modenesi, A. (2005). Regimes Monetários: Teoria e a Experiência do Real. Manole: Barueri.

Mody, A.; Ohnsorge, F. (2006). "Can domest ic policies influence inflation?'. Fundo Monetário Internacional. Working Paper, 257, Washington.

Newey, W.;West, K (1987). "Hypothesis testing with efficient method of moments estimation." International Economic Review, p. 777-787.

Pesaran, H.;Shin, Y;Smith, R (2001). "Bounds testing approaches to the analysis of level relationships." burnal of applied econometrics, 16(3). P. 289-326.

Rubio-Ramírez, J.; Waggoner, D.; Zha, T. (2010)."Structural vector autoregressions: Theory of identification and algorithms for inference". The Review of Economic Sudies, 77(2), p. 665-696.

Schwartzman, F. F. (2006). "Estimativa de curva de Phillips para o Brasil com preços desagregados". Revista de Economia Aplicada, 10, p. 137-155.

Smonsen, M. H. (1970).Inflação: gradualismo versus tratamento de choque. Apec: Ro de Janeiro.

Tombini, A. A; Alves, S A. L (2006)."The recent Brazilian disinflation process and costs". Working Paper Series, 109,Banco Central do Brasil: Brasília.

Wynne, M. A.; Kesting, E K (2007).“Openness and Inflation. Federal Reserve Bank of Dallas”. Staff Papers, 2, Texas.

Yakova, D. (2007). "lattening of the Phillips Qurve: Implications for Monetary Policy".. Working Paper, 76,Fundo Monetário Internacional, European Department: Washington.

Zvot, E; Andrews, D. W. K (1992). "Further Evidence on the Great Orash, the Oil Price Shock and the Unit-Poot Hypothesis". Journal of Business and Economic \$atistics, 10, p. 251270. 
Anexo 1. Resumo das variáveis utilizadas no modelo

Tabela 6. Resumo das Variáveis: 2001-2013

\begin{tabular}{|c|c|c|c|c|c|c|}
\hline $\begin{array}{c}\text { VARIÁVEL/ } \\
\text { ANO }\end{array}$ & $\begin{array}{c}\text { IPCA } \\
\text { (\% a.a.) }\end{array}$ & $\begin{array}{c}\text { Saldo BC } \\
\text { (US\$ milhões) }\end{array}$ & $\begin{array}{l}\text { PEXT } \\
\text { (US\$) }\end{array}$ & $\begin{array}{c}\text { TC } \\
\text { (R\$/US\$) }\end{array}$ & $\begin{array}{c}\text { VOL TC } \\
\text { (Variância } \\
\text { da TC) }\end{array}$ & $\begin{array}{c}\text { EXPECT } \\
\text { (\% a.a.) }\end{array}$ \\
\hline 2001 & 7,67 & $2.650,50$ & 45,61 & 2,36 & 0,055581 & 6,07 \\
\hline 2002 & 12,50 & $13.121,30$ & 46,81 & 2,93 & 0,290114 & 6,64 \\
\hline 2003 & 9,30 & $24.793,90$ & 54,14 & 3,08 & 0,062864 & 7,86 \\
\hline 2004 & 7,60 & $33.640,50$ & 70,59 & 2,93 & 0,013775 & 6,06 \\
\hline 2005 & 5,69 & $44.702,90$ & 100,00 & 2,43 & 0,026991 & 5,11 \\
\hline 2006 & 3,14 & $46.456,60$ & 120,67 & 2,18 & 0,001622 & 4,19 \\
\hline 2007 & 4,46 & $40.031,60$ & 133,53 & 1,96 & 0,018664 & 3,76 \\
\hline 2008 & 5,90 & $24.835,80$ & 182,15 & 1,83 & 0,070841 & 4,98 \\
\hline 2009 & 4,31 & $25.289,80$ & 116,15 & 2,00 & 0,050558 & 4,26 \\
\hline 2010 & 5,90 & $20.146,90$ & 148,54 & 1,76 & 0,00235 & 5,02 \\
\hline 2011 & 6,50 & $29.792,80$ & 195,90 & 1,68 & 0,007742 & 5,37 \\
\hline 2012 & 5,84 & $19.394,50$ & 197,95 & 1,97 & 0,014924 & 5,49 \\
\hline 2013 & 5,91 & $2.286,10$ & 195,91 & 2,17 & 0,021075 & 5,84 \\
\hline
\end{tabular}

Fonte: Elaboração própria (nov/2014). 
Anexo 2. Resultado do teste de Causalidade de Granger

Tabela 7. Testes de Causalidade de Granger

\begin{tabular}{|c|c|c|c|}
\hline & $x^{4}$ & df & Prob. \\
\hline $\begin{array}{l}\text { Variável Dependente: } \\
\text { VOL EXPEC }\end{array}$ & 12.72071 & 1 & 0.0004 \\
\hline \multirow[t]{2}{*}{$\begin{array}{l}\text { Variável Dependente: } \\
\text { EXPEC VOL }\end{array}$} & 1.681406 & 1 & 0.1947 \\
\hline & $x^{4}$ & df & Prob. \\
\hline $\begin{array}{l}\text { Variável Dependente: } \\
\text { VOL EXPEC }\end{array}$ & 13.3176 & 2 & 0.0013 \\
\hline \multirow[t]{2}{*}{$\begin{array}{l}\text { Variável Dependente: } \\
\text { EXPEC VOL }\end{array}$} & 22.79081 & 2 & 0 \\
\hline & $x^{3}$ & df & Prob. \\
\hline $\begin{array}{l}\text { Variável Dependente: } \\
\text { VOL EXPEC }\end{array}$ & 19.37064 & 3 & 0.0002 \\
\hline \multirow[t]{2}{*}{$\begin{array}{l}\text { Variável Dependente: } \\
\text { EXPEC VOL }\end{array}$} & 28.12357 & 3 & 0 \\
\hline & $x^{3}$ & df & Prob. \\
\hline $\begin{array}{l}\text { Variável Dependente: } \\
\text { VOL EXPEC }\end{array}$ & 18.0918 & 4 & 0.0012 \\
\hline \multirow[t]{2}{*}{$\begin{array}{l}\text { Variável Dependente: } \\
\text { EXPEC VOL }\end{array}$} & 28.73129 & 4 & 0 \\
\hline & $x^{6}$ & df & Prob. \\
\hline $\begin{array}{c}\text { Variável Dependente: } \\
\text { VOL }\end{array}$ & & 5 & 0.0001 \\
\hline $\begin{array}{l}\text { Variável Dependente: } \\
\text { EXPEC VOL }\end{array}$ & 38.74319 & 5 & 0 \\
\hline
\end{tabular}

Fonte: Elaboração Própria (jan/2016). 
Anexo 3. Resultados do Teste de Chow

Tabela 8 - Teste de Chow para quebra estrutural em dezembro de 2004

\begin{tabular}{|c|c|c|c|}
\hline F-statistic & 3.906276 & Prob. F(8,136) & 0.0004 \\
\hline Log likelihood ratio & 31.43908 & $\begin{array}{ll}\text { Prob. } & \text { Chi- } \\
\text { Square(8) }\end{array}$ & 0.0001 \\
\hline Wald Statistic & 31.25021 & $\begin{array}{ll}\text { Prob. } & \text { Chi- } \\
\text { Square(8) }\end{array}$ & 0.0001 \\
\hline
\end{tabular}

Fonte: Elaboração Própria (jan/2016).

Anexo 4. Resultados do Teste de Autocorrelação Godfrey e Portmanteau

Tabela 9.Testes de Autocorrelação dos Resíduos VAR-período: jan/2001 a dez/2013

\begin{tabular}{|c|c|c|c|c|c|c|c|c|}
\hline \multicolumn{3}{|c|}{ Teste LM de autocorrelação dos resíduos } & \multicolumn{6}{|c|}{ Teste de Portmanteau de autocorrelação dos resíduos } \\
\hline Defasagens & estatistica LM & Prob. & Defasagens & Q-Stat & Prob. & Adj Q-Stat & Prob. & df \\
\hline 1 & 25.64438 & 0.4268 & 1 & 2.388791 & $\mathrm{NA}^{*}$ & 2.411116 & $\mathrm{NA}^{*}$ & NA* \\
\hline 2 & 28.62911 & 0.2797 & 2 & 7.675152 & $\mathrm{NA}^{*}$ & 7.79722 & $\mathrm{NA}^{*}$ & $\mathrm{NA}^{*}$ \\
\hline 3 & 22.3695 & 0.6143 & 3 & 12.98736 & $\mathrm{NA}^{*}$ & 13.2612 & $\mathrm{NA}^{*}$ & NA* \\
\hline 4 & 28.45579 & 0.2873 & 4 & 19.76975 & $\mathrm{NA}^{*}$ & 20.30446 & $\mathrm{NA}^{*}$ & $\mathrm{NA}^{*}$ \\
\hline 5 & 30.40338 & 0.2095 & 5 & 46.93988 & 0.0233 & 42.50226 & 0.1148 & 25 \\
\hline 6 & 24.27347 & 0.5036 & 6 & 56.89059 & 0.234 & 59.39125 & 0.1706 & 50 \\
\hline 7 & 40.91422 & 0.0234 & 7 & 79.60935 & 0.3361 & 83.68458 & 0.2304 & 75 \\
\hline 8 & 19.51937 & 0.7716 & 8 & 105.2259 & 0.3408 & 111.3505 & 0.2059 & 100 \\
\hline 9 & 41.09252 & 0.0224 & 9 & 128.4708 & 0.3976 & 136.7086 & 0.2235 & 125 \\
\hline 10 & 27.48745 & 0.332 & 10 & 144.4372 & 0.6128 & 154.3041 & 0.388 & 150 \\
\hline 11 & 34.02261 & 0.1074 & 11 & 169.6816 & 0.5993 & 182.4113 & 0.335 & 175 \\
\hline 12 & 64.53826 & 0.0000 & 12 & 200.0363 & 0.486 & 216.5604 & 0.2006 & 200 \\
\hline
\end{tabular}

Fonte: Elaboração Própria (jan/2016). 
Anexo 5. Resultados do Bounds Test

Tabela 10. Bounds Test de Pesaran, Shin e Smith (2001)

\begin{tabular}{|c|c|c|c|c|}
\hline \multicolumn{3}{|c|}{ Estatística do Teste } & & \\
\hline F-statistic & \multicolumn{2}{|c|}{2.219330} & & \\
\hline & \multicolumn{2}{|c|}{ Valores Críticos } & & \\
\hline Significância & $\mathrm{I}(0)$ Bound & I(1) Bound & & \\
\hline $10 \%$ & 3.17 & 4.14 & & \\
\hline $5 \%$ & 3.79 & 4.85 & & \\
\hline $2.5 \%$ & 4.41 & 5.52 & & \\
\hline $1 \%$ & 5.15 & 6.36 & & \\
\hline \multicolumn{5}{|c|}{ Equação de Teste } \\
\hline Variável & Coeficiente & Erro Padrão & estatística $t$ & Prob. \\
\hline D(LNIPCA(-1)) & 0.619255 & 0.061355 & 10.09299 & 0 \\
\hline D(LNCAMBIO) & -0.016191 & 0.007167 & -2.259128 & 0.0254 \\
\hline $\mathrm{D}(\mathrm{LNCAMBIO}(-1))$ & 0.012015 & 0.007251 & 1.657013 & 0.0997 \\
\hline D(LNPEXT) & 0.010404 & 0.006966 & 1.493584 & 0.1375 \\
\hline D(LNPEXT(-1)) & 0.020272 & 0.006988 & 2.901111 & 0.0043 \\
\hline D(LNPEXT(-2)) & 0.000206 & 0.000758 & 0.271365 & 0.7865 \\
\hline $\mathrm{C}$ & 0.015272 & 0.014988 & 1.018971 & 0.3099 \\
\hline LNCAMBIO(-1) & 0.000806 & 0.001639 & 0.491881 & 0.6236 \\
\hline LNPEXT(-1) & 0.003919 & 0.0025 & 1.567839 & 0.1191 \\
\hline LNIPCA(-1) & -0.00408 & 0.00296 & -1.378221 & 0.1703 \\
\hline R-squared & 0.625123 & \multicolumn{2}{|c|}{ Mean dependent var } & 0.005256 \\
\hline Adjusted R-squared & 0.601529 & \multicolumn{2}{|c|}{ S.D. dependent var } & 0.003878 \\
\hline S.E. of regression & 0.002448 & \multicolumn{2}{|c|}{ Akaike info criterion } & -9.12412 \\
\hline Sum squared resid & 0.000857 & \multicolumn{2}{|c|}{ Schwarz criterion } & -8.92605 \\
\hline Log likelihood & 707.9948 & \multicolumn{2}{|c|}{ Hannan-Quinn criter. } & -9.04366 \\
\hline F-statistic & 26.49534 & \multicolumn{2}{|c|}{ Durbin-Watson stat } & 2.108848 \\
\hline Prob(F-statistic) & 0 & & & \\
\hline
\end{tabular}

Fonte: Elaboração Própria (jan/2016). 
Anexo 6. Resultados do Modelo ARDL

Tabela 11. Modelo ARDL - Período 1: jan/2001 a dez/2014

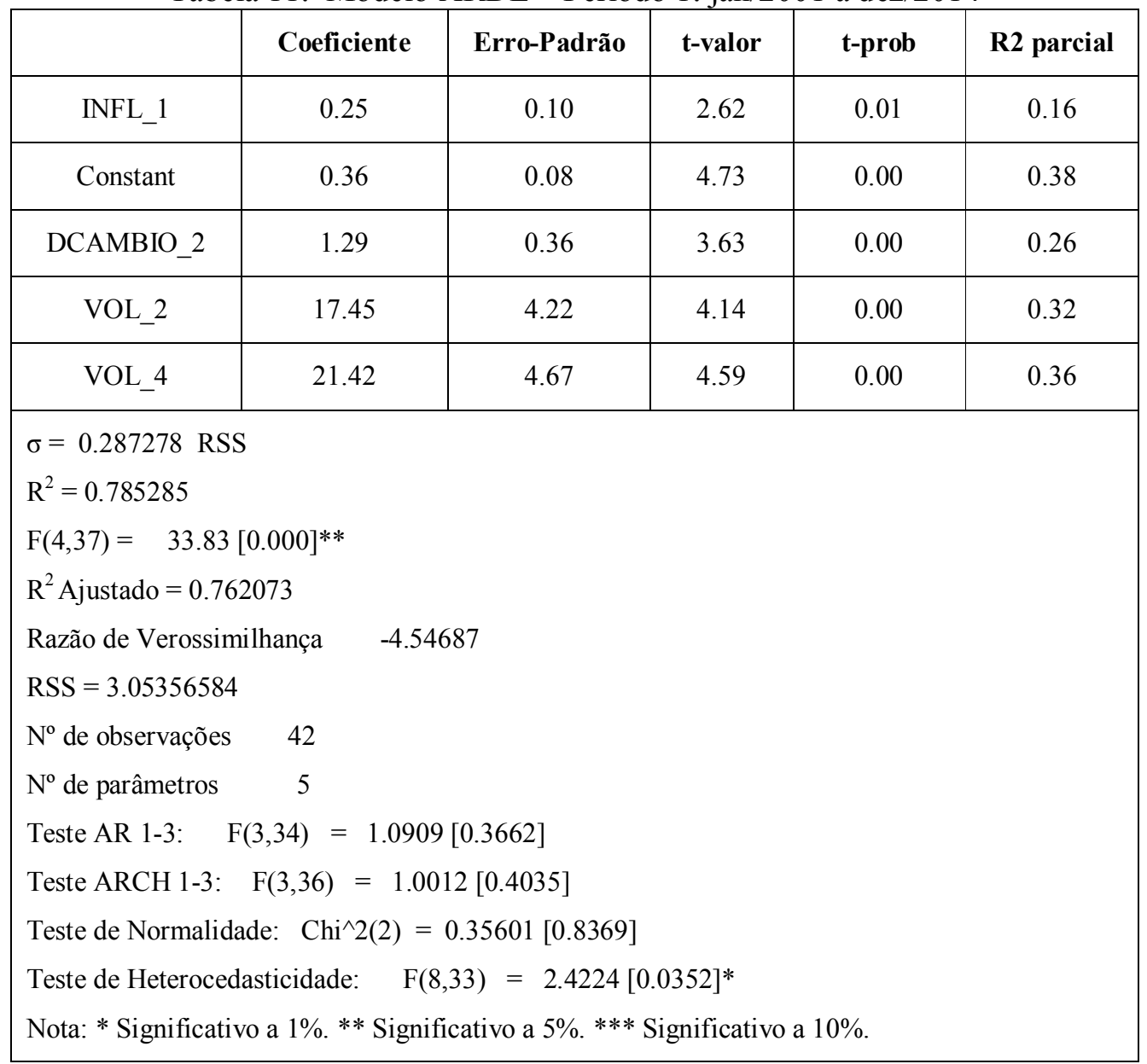

Fonte: Elaboração Própria (nov/2014). 
Tabela 12. Modelo ARDL - Período 1: jan/2005 a dez/2013

\begin{tabular}{|c|c|c|c|c|c|}
\hline & Coeficiente & $\begin{array}{c}\text { Erro- } \\
\text { Padrão }\end{array}$ & t-valor & t-prob & R2 parcial \\
\hline INFL_1 & 0.57 & 0.07 & 7.94 & 0.00 & 0.38 \\
\hline Constant & 0.20 & 0.04 & 5.49 & 0.00 & 0.23 \\
\hline DPEXT_1 & 0.02 & 0.00 & 4.26 & 0.00 & 0.15 \\
\hline DCAMBIO_4 & 0.61 & 0.22 & 2.77 & 0.01 & 0.07 \\
\hline VOL_1 & -17.63 & 8.29 & -2.13 & 0.04 & 0.04 \\
\hline \multicolumn{6}{|l|}{$\sigma=0.164613$} \\
\hline \multicolumn{6}{|l|}{$\mathrm{R}^{2}=0.487604$} \\
\hline \multicolumn{6}{|c|}{$\mathrm{F}(4,103)=24.5[0.000]^{* *}$} \\
\hline \multicolumn{6}{|c|}{$\mathrm{R}^{2}$ Ajustado $=0.467705$} \\
\hline \multicolumn{6}{|c|}{ Razão de Verossimilhança $\quad 44.1634$} \\
\hline \multicolumn{6}{|l|}{$\mathrm{RSS}=2.79103554$} \\
\hline \multicolumn{6}{|c|}{$\mathrm{N}^{\mathrm{o}}$. de observações 108} \\
\hline \multicolumn{6}{|l|}{$\mathrm{N}^{\circ} \mathrm{o}$. de parâmetros } \\
\hline \multicolumn{6}{|c|}{ Teste AR 1-7: $\quad F(7,96)=1.0363[0.4111]$} \\
\hline \multicolumn{6}{|c|}{ Teste ARCH 1-7: $\quad F(7,94)=0.25549[0.9692]$} \\
\hline \multicolumn{6}{|c|}{ Teste de normalidade: $\mathrm{Chi}^{\wedge} 2(2)=0.67750[0.7127]$} \\
\hline \multicolumn{6}{|c|}{ Teste de heterocedasticidade: $\quad \mathrm{F}(8,99)=1.3477[0.2292]$} \\
\hline
\end{tabular}

Fonte: Elaboração Própria (nov/2014). 
Anexo 7. Decomposição da Variância

Tabela 13.Decomposição da Variância - período: jan/2001 a dez/2004

\begin{tabular}{|c|c|c|c|c|c|c|}
\hline Período & S.E. & DPEXT & DCAMBIO & VOL & BC & INFL \\
\hline 1 & 0.341477 & 11.24589 & 6.067328 & 0.000000 & 0.000000 & 82.68678 \\
\hline 2 & 0.377109 & 10.37624 & 5.700931 & 0.297617 & 0.838115 & 82.78710 \\
\hline 3 & 0.456325 & 13.05912 & 3.935885 & 23.49916 & 0.998800 & 58.50703 \\
\hline 4 & 0.498239 & 18.10150 & 3.303641 & 26.86219 & 1.802649 & 49.93002 \\
\hline 5 & 0.536776 & 26.20761 & 3.151371 & 25.34206 & 2.263697 & 43.03526 \\
\hline 6 & 0.567492 & 29.05373 & 3.496340 & 23.57123 & 5.113346 & 38.76535 \\
\hline 7 & 0.586679 & 30.87932 & 3.774733 & 22.45818 & 6.067012 & 36.82076 \\
\hline 8 & 0.599814 & 31.23024 & 4.019122 & 21.82660 & 7.333319 & 35.59072 \\
\hline 9 & 0.606786 & 31.18651 & 4.126145 & 21.34269 & 8.173891 & 35.17077 \\
\hline 10 & 0.610718 & 31.05354 & 4.195754 & 21.06898 & 8.865183 & 34.81654 \\
\hline 11 & 0.613524 & 30.80367 & 4.208710 & 20.89021 & 9.527736 & 34.56967 \\
\hline 0.615137 & 30.64510 & 4.202743 & 20.80196 & 9.944165 & 34.40603 \\
\hline
\end{tabular}

Fonte: Elaboração Própria (nov/2014).

Tabela 14.Decomposição da Variância - período: jan/2005 a dez/2013

\begin{tabular}{|c|c|c|c|c|c|c|}
\hline Período & S.E. & DPEXT & DCAMBIO & VOL & BC & INFL \\
\hline 1 & 0.170140 & 0.000000 & 0.000000 & 0.000000 & 0.000000 & 100.0000 \\
\hline 2 & 0.202955 & 6.176448 & 0.364491 & 2.109093 & 0.799191 & 90.55078 \\
\hline 3 & 0.216996 & 8.543466 & 1.159782 & 5.611038 & 1.862701 & 82.82301 \\
\hline 4 & 0.223390 & 8.965503 & 1.949793 & 7.739978 & 2.584624 & 78.76010 \\
\hline 5 & 0.226105 & 8.973898 & 2.450495 & 8.662574 & 2.919039 & 76.99399 \\
\hline 6 & 0.227170 & 8.945158 & 2.700979 & 9.010250 & 3.043898 & 76.29971 \\
\hline 7 & 0.227566 & 8.928767 & 2.811225 & 9.134039 & 3.085116 & 76.04085 \\
\hline 8 & 0.227710 & 8.921734 & 2.856454 & 9.177204 & 3.097812 & 75.94680 \\
\hline 9 & 0.227761 & 8.918969 & 2.874280 & 9.192126 & 3.101565 & 75.91306 \\
\hline 10 & 0.227780 & 8.917919 & 2.881124 & 9.197245 & 3.102641 & 75.90107 \\
\hline 11 & 0.227786 & 8.917528 & 2.883699 & 9.198981 & 3.102939 & 75.89685 \\
\hline 12 & 0.227788 & 8.917385 & 2.884650 & 9.199562 & 3.103018 & 75.89539 \\
\hline
\end{tabular}

Fonte: Elaboração Própria (nov/2014). 
Anexo 8. Coeficientes de Repasse

Tabela 15. Coeficientes de repasse - período: jan/2001 a dez/2004

\begin{tabular}{|c|c|c|c|c|}
\hline Período & Repasse DPEXT & Repasse DCAMBIO & Repasse VOL & Repasse BC \\
\hline 1 & -0.03 & -1.18 & 0.00 & 0.00 \\
\hline 2 & -0.02 & -0.87 & 1.83 & 0.00 \\
\hline 3 & 0.01 & -0.85 & 21.10 & 0.00 \\
\hline 4 & 0.03 & -1.30 & 32.16 & 0.00 \\
\hline 5 & 0.05 & -2.98 & 36.81 & 0.00 \\
\hline 6 & 0.07 & -5.72 & 37.58 & 0.00 \\
\hline 7 & 0.09 & -8.00 & 40.90 & 0.00 \\
\hline 8 & 0.11 & -8.82 & 43.03 & 0.00 \\
\hline 9 & 0.12 & -9.42 & 44.14 & 0.00 \\
\hline 10 & 0.13 & -9.17 & 44.43 & 0.00 \\
\hline 11 & 0.13 & -9.02 & 44.12 & 0.00 \\
\hline 12 & 0.14 & -8.75 & 44.08 & 0.00 \\
\hline
\end{tabular}

Fonte: Elaboração Própria (nov/2014).

Tabela 16. Coeficientes de repasse - período: jan/2005 a dez/2013

\begin{tabular}{|c|c|c|c|c|}
\hline Período & Repasse DPEXT & Repasse DCAMBIO & Repasse VOL & Repasse BC \\
\hline 1 & 0.00 & 0.00 & 0.00 & 0.00 \\
\hline 2 & 0.01 & -0.15 & -15.72 & 0.00 \\
\hline 3 & 0.02 & -0.33 & -34.45 & 0.00 \\
\hline 4 & 0.03 & -0.51 & -48.18 & 0.00 \\
\hline 5 & 0.03 & -0.64 & -56.73 & 0.00 \\
\hline 6 & 0.03 & -0.74 & -61.86 & 0.00 \\
\hline 7 & 0.03 & -0.80 & -64.88 & 0.00 \\
\hline 8 & 0.03 & -0.84 & -66.70 & 0.00 \\
\hline 9 & 0.03 & -0.87 & -67.79 & 0.00 \\
\hline 10 & 0.04 & -0.88 & -69.44 & 0.00 \\
\hline 12 & 0.04 & -0.90 & 0.00 \\
\hline
\end{tabular}

Fonte: Elaboração Própria (nov/2014). 
Anexo 9. Funções de Impulso Resposta

Figura 2. Resposta do IPCA a um choque em: preços externos, câmbio, volatilidade cambial e balança comercial (VAR): 2001-2004 - Fatoração Estrutural
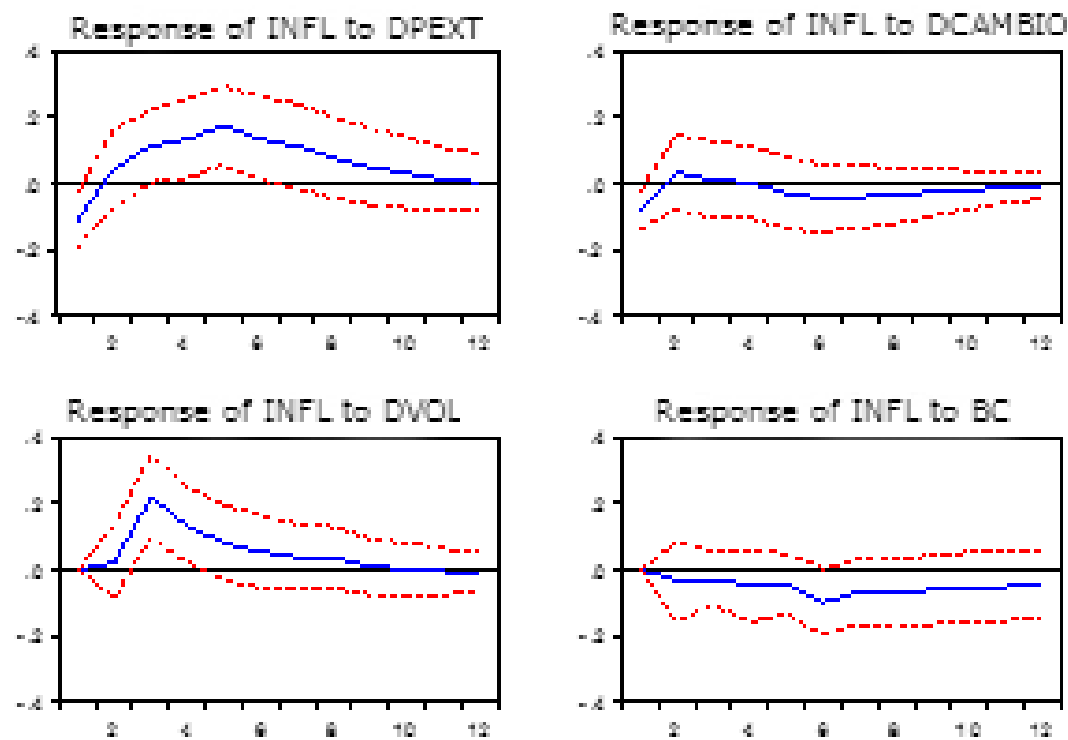

Fonte: Elaboração Própria (nov/2014).

Figura 3. Resposta do IPCA a um choque em: preços externos, câmbio, volatilidade cambial e balança comercial (VAR): 2005-2013 - Fatoração Estrutural
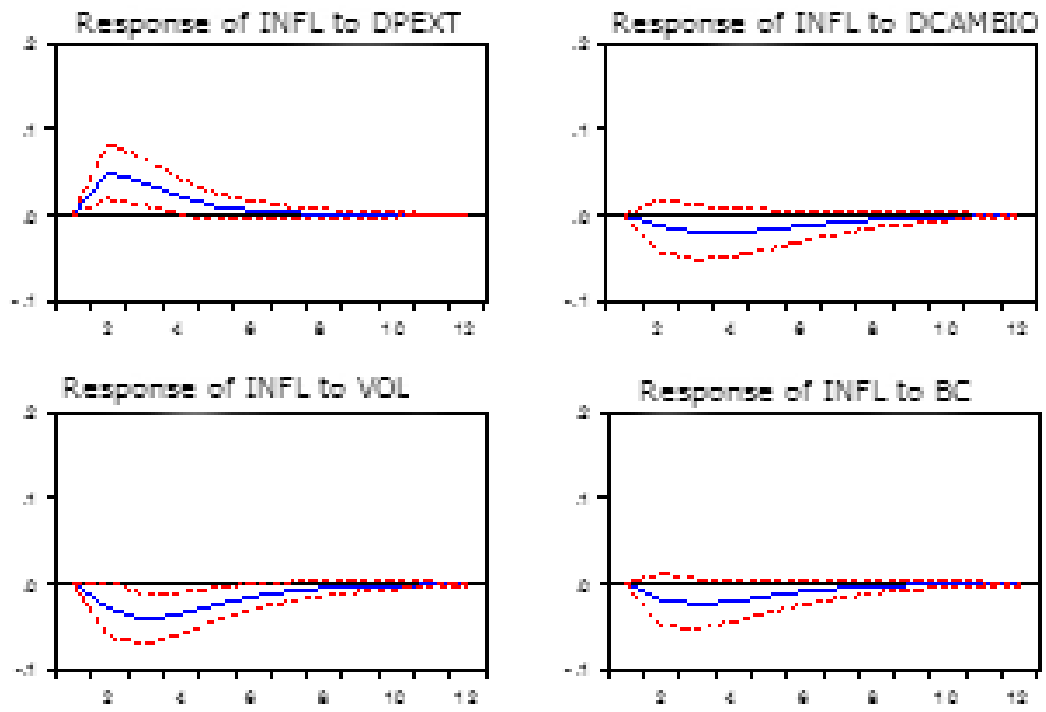

Fonte: Elaboração Própria (nov/2014). 